\title{
Effective elimination of chronic lymphocytic leukemia cells in the stromal microenvironment by a novel drug combination strategy using redox-mediated mechanisms
}

\author{
WAN ZHANG ${ }^{1}$, HELENE PELICANO $^{2}$, RAN YIN $^{3}$, JUNYI ZENG $^{1}$, TONG WEN $^{1}$, LU DING $^{1}$ and RUIBIN HUANG ${ }^{1}$ \\ ${ }^{1}$ Department of Leukemia, The First Affiliated Hospital of Nanchang University, Nanchang, Jiangxi 330006, P.R. China; \\ ${ }^{2}$ Department of Molecular Pathology, The University of Texas MD Anderson Cancer Center, Houston, TX 77054, USA; \\ ${ }^{3}$ Department of Cardiology, The First Affiliated Hospital of Nanchang University, \\ Nanchang, Jiangxi 330006, P.R. China
}

Received November 19, 2014; Accepted August 25, 2015

DOI: $10.3892 / \mathrm{mmr} .2015 .4364$

\begin{abstract}
Chronic lymphocytic leukemia (CLL) is the most common type of adult leukemia, and is currently incurable due to drug resistance. A previous study indicated that the redox interaction between bone marrow stromal cells and leukemia cells profoundly affected CLL cell viability and drug response. The present study aimed to further investigate the effect of the redox interaction on drug resistance of CLL cells in the bone marrow microenvironment, and to assess a novel redox-mediated strategy to eliminate stromal-protected CLL cells, and thus to achieve maximum therapeutic efficacy of antileukemic drugs. Histone deacetylase inhibitor suberoylanilide hydroxamic acid (SAHA) is a potent novel anticancer agent, however, it exerts limited activity in patients with CLL. The results of the present study demonstrated that SAHA facilitated stromal-mediated glutathione upregulation in the CLL cells, contributing to drug resistance. The addition of $\beta$-phenylethyl isothiocyanate (PEITC) induced severe depletion of stromal and SAHA-upregulated glutathione, enhanced SAHA-mediated reactive oxygen species accumulation in the CLL cells and caused oxidation of mitochondrial cardiolipin, leading to substantial cell death. The results further demonstrated that stromal cells and SAHA markedly upregulated antiapoptotic protein expression levels of myeloid cell leukemia 1 (Mcl1) in CLL the cells. By inducing protein deglutathionylation and degradation, PEITC suppressed the expression of Mcl1 in co-cultured CLL cells, and increased SAHA sensitivity. The combination of SAHA and PEITC
\end{abstract}

Correspondence to: Dr Wan Zhang, Department of Leukemia, The First Affiliated Hospital of Nanchang University, 17 Yongwaizheng Street, Nanchang, Jiangxi 330006, P.R. China

E-mail: zhangwan519@hotmail.com

Key words: chronic lymphocytic leukemia, bone marrow stromal cell, redox modulation, suberoylanilide hydroxamic acid, $\beta$-phenylethyl isothiocyanate, combination strategy enabled the induction of marked apoptosis of CLL cells co-cultured with bone marrow stromal cells. The present study provided a preclinical rationale, which warrants further clinical investigation for the potential use of SAHA/PEITC as a novel combination treatment strategy for CLL.

\section{Introduction}

Chronic lymphocytic leukemia (CLL) is the most prevalent type of adult leukemia in western countries (1). Failure to eliminate residual leukemia cells, which are resistant to drug treatment, and the eventual reemergence of the leukemia cell population continue to be major clinical challenges, and CLL remains an incurable disease (2). Although several anticancer drugs are effective at eliminating CLL cells in vitro, leukemia cells are much more resistant to drug treatment in vivo. Increasing evidence suggests that the bone marrow stroma may provide a tissue microenvironment, which promotes the survival of CLL cells and facilitates drug resistance $(3,4)$. Therefore, the development of novel therapeutic strategies to inhibit the protective effect of stromal cells is critical for the effective elimination of malignant cells in vivo.

CLL cells are under intrinsic oxidative stress and exhibit high spontaneous apoptosis with rapid glutathione (GSH) depletion in vitro (5-7). GSH is important in CLL cells, counteracting oxidative stress and maintaining the redox balance (8). By relieving oxidative stress, GSH also reduces the activity of reactive oxygen species (ROS)-generating drugs (9). Our previous study revealed that bone marrow stromal cells convert cystine to cysteine, allowing CLL cells to synthesize GSH (8). This metabolic interaction between CLL cells and bone marrow stromal cells increases the expression levels of GSH in CLL cells, and promotes cell survival. Interruption of this biochemical interaction using the GSH-depletion agent, $\beta$-phenylethyl isothiocyanate (PEITC), significantly sensitizes CLL cells to drug treatment in the stromal environment (8). Therefore, PEITC is a potent candidate for the development of combination treatment strategies to overcome microenvironment-mediated drug resistance in CLL cells. 
Histone deacetylase inhibitors (HDACIs) are emerging as a potent novel class of anticancer agents (10). A previous study demonstrated that HDACI triggers apoptosis via the intrinsic apoptotic signaling pathway following early generation of ROS in acute myeloid leukemia (AML) cell lines, and inhibition of ROS generation protects leukemia cells from apoptosis (11). Our previous study suggested that HDACI-induced ROS generation leads to the upregulation of GSH-associated enzymatic genes in myeloid leukemia cells, and confers resistance to HDACI toxicity (12). Therefore, the redox status of malignant cells affects HDACI sensitivity, and modulating ROS levels is important for the design of drug combination strategies to overcome HDACI resistance.

The HDACI suberoylanilide hydroxamic acid (SAHA or Vorinostat) is the first HDACI to be approved for use in the treatment of cutaneous T-cell lymphoma (13). Preclinical studies have reported that SAHA exerts promising antitumor activity in CLL cells (14-16). However, initial monotherapy clinical trials using various HDACIs in patients with CLL exhibited limited efficacy $(17,18)$, which indicates that the leukemia microenvironment in vivo may affect drug sensitivity. The mechanisms underlying the role of SAHA in CLL cells remains to be elucidated, particularly in the context of microenvironment-mediated redox changes in CLL cells. The aims of the present study were to examine the role of ROS generation in SAHA toxicity in CLL cells, to investigate the significance of bone marrow stromal cell-mediated redox changes in protection against SAHA-induced ROS stress and cell death in CLL cells, to evaluate the effect of SAHA in combination with the PEITC redox-modulating compound, and to determine its ability to eliminate stromal-protected CLL cells.

\section{Materials and methods}

Reagents. SAHA, PEITC, N-acetylcysteine (NAC), metaphosphoric acid, propidium iodide (PI), anti- $\beta$-actin, paraformaldehyde, Triton X-100 and bovine serum albumin (BSA) were purchased from Sigma-Aldrich (St. Louis, MO, USA). CM-H $\mathrm{H}_{2}$ DCF-DA, nonyl acridine orange (NAO), Rhodamine-123 and mounting medium, supplemented with 4',6-diamidino-2-phenylindole (DAPI), were purchased from Invitrogen Life Technologies (Carlsbad, CA, USA). The Annexin V-fluorescein isothiocyanate (FITC), Z-VAD, a caspase-3 activity assay kit and recombinant active caspase-3 were purchased from BD Biosciences (San Jose, CA, USA). Ficoll-lite Lympho $\mathrm{H}$ was purchased from Atlanta Biologicals, Inc. (Flowery Branch, GA, USA). (S)-4-carboxyphenylglycine (CPG) was acquired from Tocris Bioscience (Ellisville, MO, USA). The GSH assay kit was purchased from Cayman Chemical Company (Ann Arbor, MI, USA). Rabbit anti-human $\gamma$-glutamyl cysteine synthetase (GCLC; cat. no. sc-28965), rabbit anti-human nuclear factor-E2-related factor 2 (Nrf2; cat. no. sc-13032), and rabbit anti-human myeloid cell leukemia 1 (Mcl1; cat. no. sc-819) were purchased from Santa Cruz Biotechnology, Inc. (Santa Cruz, CA, USA). Sealed modular incubator chambers were purchased from Billups-Rothenberg, Inc. (San Diego, CA, USA).

Cell lines and primary CLL cells. The HS5 human bone marrow stromal cell line immortalized by E6/E7 (11), was obtained from American Type Culture Collection (Manassas, VA, USA). A total of 62 patients (male and female; aged 38-85 years) diagnosed with typical B-CLL were recruited from the First Affiliated Hospital of Nanchang University (Nanchang, China) in the present study. The diagnosis was based on clinical criteria and laboratory features, according to National Cancer Institute Criteria (19). All patients provided written informed consent, and the present study was approved by the ethics committee of The First Affiliated Hospital of Nanchang University. In all experiments, CLL cells were isolated from peripheral blood samples, which were collected from the patients, by density gradient centrifugation (20). Briefly, $5 \mathrm{ml}$ blood was slowly added to a Falcon tube containing $6 \mathrm{ml}$ pre-warmed Fico/Lite LymphoH buffer (Atlanta Biological, Lawrenceville, GA, USA) and then centrifuged at $435 \mathrm{x}$ g for $20 \mathrm{~min}$ at room temperature. The isolated CLL cells was washed with pre-warmed PBS and incubated in RPMI-1640 medium (Cellgro; Mediatech, Inc., Hendon, VA, USA) supplemented with $10 \%$ fetal bovine serum, penicillin (100 U/ml) and streptomycin (100 $\mu \mathrm{g} / \mathrm{ml}$; all from Cellgro; Mediatech, Inc.) overnight prior to experimentation.

Cell viability assays. The effect of bone marrow stromal cells on drug-induced apoptosis in CLL cells was determined, as previously described (8). Briefly, HS5 cells $\left(5 \times 10^{4}\right.$ cells $\left./ \mathrm{ml}\right)$ were seeded in 24-well plates and allowed to adhere and grow overnight prior to the addition of CLL cells. The CLL cells were isolated from the blood samples and incubated overnight with RPMI-1640 medium supplemented with $10 \%$ fetal bovine serum, penicillin $(100 \mathrm{U} / \mathrm{ml})$ and streptomycin $(100 \mu \mathrm{g} / \mathrm{ml})$, and then transferred $\left(1 \times 10^{6}\right)$ into 24 -well plates with or without the pre-seeded stromal cells at a density of $5 \times 10^{4}$ cells per well. Following co-culture for 1 day, the CLL cells were treated with SAHA and PEITC under different treatment conditions. To inhibit cystine uptake by the stromal cells, (S)-4-CPG was added at the beginning of the stromal cell seeding. To inhibit cystine uptake by the stromal cells, the CLL and HS5 cells in co-culture were incubated with S-4-CPG $(500 \mu \mathrm{M})$ for $24 \mathrm{~h}$, and then exposed to SAHA $(2 \mu \mathrm{M})$ for $48 \mathrm{~h}$. Cell viability was determined using flow cytometry (FACSCalibur; BD Biosciences), following double-staining with Annexin V-FITC and PI. All assays were repeated at least three times using primary CLL cells from different patient samples.

Analysis of cellular GSH levels. GSH was quantified using a GSH assay kit, based on enzymatic recycling reactions. Following CLL cell culture under various experimental conditions, the cells were collected, sonicated at speed four (five times) at $4^{\circ} \mathrm{C}$, and de-proteinated by precipitation with an equal volume of $10 \%$ metaphosphoric acid (Sigma-Aldrich). The precipitated proteins were removed by centrifugation at $3,000 \mathrm{x} \mathrm{g}$ for $5 \mathrm{~min}$ at $4^{\circ} \mathrm{C}$. The supernatant was collected, neutralized with triethanolamine (cat. no. T58300; Sigma-Aldrich) and assayed for GSH (reduced) and GSSG (oxidized) using a Cayman GSH assay kit, according to the manufacturer's instructions. The data were obtained from triplicate measurements.

Detection of cellular ROS levels. The cellular ROS levels were measured by incubating the CLL cells $\left(1 \times 10^{6}\right.$ cells) with 
$1 \mu \mathrm{M} \mathrm{CM}-\mathrm{H}_{2} \mathrm{DCF}-\mathrm{DA}$ for $60 \mathrm{~min}$ at $37^{\circ} \mathrm{C}$ in the dark, followed by analysis using flow cytometry, as previously described (8). The ROS levels in the viable cells were determined with a chemical probe (CM- $\left.\mathrm{H}_{2} \mathrm{DCF}-\mathrm{DA}\right)$, using forward scatter/side scatter gating to differentiate dead and viable cells, as previously described (8).

Analysis of mitochondrial oxidative damage, cytochrome c release, caspase-3 activation and mitochondrial transmembrane potential. Cardiolipin is the predominant lipid component of the internal mitochondrial membrane, and contributes to the maintenance of its structure (21). The fluorescent dye, NAO, which specifically binds to cardiolipin, is used to measure the oxidation of cardiolipin (22). Following CLL cell culture in the different conditions, the cells were treated with or without SAHA, and the samples were labeled with $50 \mathrm{nM}$ NAO for $15 \mathrm{~min}$ and analyzed using flow cytometry, as previously described (23). A cytochrome $c$ release kit (EMD Millipore, San Diego, CA, USA) and caspase-3 activation assay kit were used to measure the loss of mitochondrial cytochrome $c$ and the levels of activated caspase-3, according to the manufacturer's instructions. Rhodamine-123 (Invitrogen Life Technologies) was used to evaluate mitochondrial transmembrane potential. The CLL cells were labeled with $1 \mu \mathrm{M}$ Rhodamine- 123 for $60 \mathrm{~min}$ and analyzed using flow cytometry, as previously described (24).

Western blot analysis. The CLL cells were solubilized in buffer containing $10 \mathrm{mM}$ Tris-Hcl (pH 7.6; car. no. T1503; Sigma-Aldrich), 1\% SDS (cat. no. L3771; Sigma-Aldrich) and protease inhibitor (cat. no. 11836170001; Roche Diagnostics; Pleasanton, CA, USA). The proteins were quantified using a bicinchoninic acid assay protein assay kit (cat. no. 23225; Pierce Biotechnology, Rockford, IL, USA), and then adjusted to $2 \mu \mathrm{g} /$ $\mathrm{ml}$ with sample buffer containing $250 \mathrm{mM}$ Tris-Hcl (pH 6.8; cat. no. T1503; Sigma-Aldrich), 4\% SDS (cat. no. L3771; Sigma-Aldrich), 10\% glycerol (cat. no. G5516; Sigma-Aldrich), $0.006 \%$ bromophenol blue (cat. no. B0126; Sigma-Aldrich) and $2 \%$ mercaptoetanol (cat. no. M6250; Sigma-Aldrich). The cell lysates were heated at $95^{\circ} \mathrm{C}$ for $10 \mathrm{~min}$, and equal quantities of protein were electrophoresed on SDS-PAGE in a Mini-Protean II Dual Slab Cell (Bio-Rad Laboratories, Inc., Hercules, CA, USA). The proteins were then transferred onto nitrocellulose membranes using a Mini Trans-Blot Transfer Cell (Bio-Rad Laboratories, Inc.). The transfer was performed at $4^{\circ} \mathrm{C}$ for $2 \mathrm{~h}$ at a constant voltage setting of $110 \mathrm{~V}$. The blots were blocked in $5 \%$ nonfat milk for $1 \mathrm{~h}$ at room temperature. The membranes were then probed with the following primary antibodies: Rabbit anti-human GCLC polyclonal antibody (cat. no. sc-28965, Santa Cruz Biotechnology, Inc.) at a 1:1,000 dilution; rabbit anti-human Nrf2 polyclonal antibody cat. no. sc-13032; Santa Cruz Biotechnology, Inc.) at a 1:1,000 dilution; rabbit anti-human Mcl1 polyclonal antibody (cat. no. sc-819; Santa Cruz Biotechnology, Inc.) at a 1:1,000 dilution;and mouse anti-human actin monoclonal antibody (cat. no. MA5-11869; Pierce Biotechnology) at a 1:10,000 dilution. After $2 \mathrm{~h}$ incubation at room temperature, the blots were washed three times for 10 min in PBS containing 0.1\% Tween-20 (cat. no. P1379; Sigma-Aldrich), and then incubated for $1 \mathrm{~h}$ at room temperature in the following secondary antibodies: Goat anti-rabbit polyclonal antibody (cat. no. 31210; Pierce Biotechnology) for GCLC, Nrf2 and Mcl1 detection at a 1:3,000 dilution; and goat anti-mouse polyclonal antibody (cat. no. 62-6700; Pierce Biotechnology) for actin detection at a 1:20,000 dilution. The blots were then washed three times for $10 \mathrm{~min}$ in the same buffer as above, incubated in enhanced chemiluminescence detection reagents (GE Healthcare Life Sciences, Chalfont, UK) for $1 \mathrm{~min}$. The blots were then exposed to an X-OMAT AR x-ray film (Kodak, Rochester, NY, USA) for between $10 \mathrm{sec}$ and $5 \mathrm{~min}$.

Immunofluorescence and confocal microscopy. The CLL cells were cytospun at $20 \mathrm{xg}$ for $5 \mathrm{~min}$ at room temperature, fixed with $3.7 \%$ (v/v) paraformaldehyde, permeabilized with $0.2 \%$ Triton X-100 and blocked with 5\% (w/v) BSA. The fixed CLL cells were incubated with rabbit anti-human polyclonal Nrf2 antibody (1:50; cat no. sc-13032; Santa Cruz Biotechnology, Inc.), at $4^{\circ} \mathrm{C}$ overnight, followed by incubation with Alexa-Fluor-594 goat anti-rabbit polyclonal antibody (1:400; cat. no. A11594; Molecular Probes at room temperature for $1 \mathrm{~h}$. Finally, the slides were washed with phosphate-buffered saline, mounted and counterstained with mounting medium supplemented with DAPI prior to examination with a Nikon Eclipse TE2000 confocal microscope and analysis with Nikon EZ-C1 3.80 software (Nikon Corporation, Tokyo, Japan).

Determination of the effect of oxygen levels on CLL cell viability. HS5 cells $\left(5 \times 10^{4}\right.$ cells $\left./ \mathrm{ml}\right)$ were seeded in 24 -well plates and allowed to adhere and grow overnight prior to the addition of CLL cells. The CLL cells were isolated from blood samples and incubated overnight at $37^{\circ} \mathrm{C}$ with RPMI 1640 medium supplemented with $10 \%$ fetal bovine serum, penicillin $(100 \mathrm{U} / \mathrm{ml})$ and streptomycin $(100 \mu \mathrm{g} / \mathrm{ml})$. Subsequently $1 \times 10^{6}$ CLL cells were transferred into 24 -well plates with or without a pre-seeded stromal cell layer at a density of $5 \times 10^{4}$ cells per well, and incubated in normoxic or hypoxic conditions (5 and $2 \%$, respectively) for 1 day at $37^{\circ} \mathrm{C}$. The CLL cells were then treated with SAHA $(2 \mu \mathrm{M})$ for $43 \mathrm{~h}$, followed by PEITC $(5 \mu \mathrm{M})$ for $5 \mathrm{~h}$, at various oxygen levels, at $37^{\circ} \mathrm{C}$. Cell viability was determined using flow cytometry following double-staining with Annexin V and PI. Hypoxic culture conditions were created by incubating the cells in a sealed modular incubator chamber flushed with $5 \%$ or $2 \%$ oxygen, $5 \%$ carbon dioxide and balanced nitrogen.

Reverse transcription-quantitative polymerase chaIn reaction (RT-qPCR) analysis. Total RNA was isolated from the cells using an RNeasy kit (Qiagen, Valencia, CA, USA), followed by DNAase (Ambion Life Technologies, Austin, TX, USA) treatment to remove any contaminating DNA. The RNA was quantitated spectrophotometrically at $260 \mathrm{~nm}$ (Du800 nucleic acid/protein analyzer; Beckman-Coulter, Fullerton, CA, USA). Reverse transcription was performed using TaqMan Reverse Transcription reagents (Applied Biosystems Life Technologies, Foster City, CA, USA). Gene-specific primers for GCLC (forward 5'-AGAGAAGGGGAAAGGACAA-3' and reverse 5'-GTGAACCCAGGACAGCCTAA-3') and $\beta$-actin (forward 5'-TCACCCACACTGTGCCCATCTACGA-3' and reverse 5'-TGAGGTAGTCAGTCAGGTCCCG-3') were used to amplify a segment of reverse transcribed mRNA using 
Table I. Cytotoxicity of SAHA, PEITC and their combination in CLL cells co-cultured with HS5 cells.

\begin{tabular}{|c|c|c|c|c|c|}
\hline \multirow[b]{3}{*}{ Patient } & \multicolumn{4}{|c|}{ Residual viable cells (\%) } & \multirow{3}{*}{$\begin{array}{c}\text { Combination } \\
\text { effect }\end{array}$} \\
\hline & \multirow[b]{2}{*}{$2 \mu \mathrm{M}$ SAHA } & \multirow[b]{2}{*}{$5 \mu \mathrm{M}$ PEITC } & \multicolumn{2}{|c|}{$2 \mu \mathrm{M}$ SAHA $+5 \mu \mathrm{M}$ PEITC } & \\
\hline & & & Observed & Predicted & \\
\hline 1 & 0.6 & 0.37 & 0.10 & 0.22 & >additive \\
\hline 2 & 0.54 & 0.53 & 0.08 & 0.29 & >additive \\
\hline 3 & 0.78 & 0.45 & 0.13 & 0.35 & >additive \\
\hline 4 & 0.41 & 0.27 & 0.05 & 0.11 & >additive \\
\hline 5 & 0.81 & 0.39 & 0.21 & 0.32 & >additive \\
\hline 6 & 0.65 & 0.31 & 0.17 & 0.20 & >additive \\
\hline 7 & 0.72 & 0.35 & 0.12 & 0.25 & >additive \\
\hline 8 & 0.59 & 0.29 & 0.07 & 0.17 & $>$ additive \\
\hline 9 & 0.66 & 0.32 & 0.11 & 0.21 & >additive \\
\hline 10 & 0.71 & 0.40 & 0.19 & 0.28 & >additive \\
\hline
\end{tabular}

CLL cells in co-culture were exposed to SAHA $(2 \mu \mathrm{M} ; 48 \mathrm{~h})$, PEITC $(5 \mu \mathrm{M} ; 5 \mathrm{~h})$ or the two combined. PEITC was added during the last $5 \mathrm{~h}$ of incubation. Cell viability was analyzed using an Annexin V/propidium iodide assay. The numbers indicate the percentage of viable cells. The predicted viable cells were calculated by multiplying the separate percentage of viable cells in the SAHA and PEITC-treated cells. The combination effect is considered more than additive when the observed value is less than the predicted value. CLL, chronic lymphocytic leukemia; SAHA, suberoylanilide hydroxamic acid; PEITC, $\beta$-phenylethyl isothiocyanate.

an ABI 7700 sequence detection system and SYBR reagents (Invitrogen Life Technologies). $\beta$-actin was used as the internal control gene. Human gene-specific primers were synthesized by Invitrogen Life Technologies. PCR reactions were prepared with final concentrations of $1 \mu \mathrm{g}$ cDNA and $200 \mathrm{nM}$ primers. Thermal cycling conditions comprised a pre-heating cycle for $10 \mathrm{~min}$ at $95^{\circ} \mathrm{C}$ for 50 cycles, then $95^{\circ} \mathrm{C}$ for $25 \mathrm{sec}, 60^{\circ} \mathrm{C}$ for $40 \mathrm{sec}$, and $70^{\circ} \mathrm{C}$ for $40 \mathrm{sec}$. Each measurement was performed in triplicate, and the threshold cycle and the fractional cycle number was determined. $\beta$-actin was used as the internal control gene.

Statistical analysis. All experiments were performed on CLL cells from at least three patients, and stromal cells from three separate culture flasks were used. Statistical significance was analyzed using Student's $t$-test. $\mathrm{P}<0.05$ was considered to indicate a statistically significant difference. Bar graphs and plots were generated using GraphPad Prism 5 software (GraphPad Software, Inc., La Jolla, CA, USA).

\section{Results}

Bone marrow stromal cells increase the expression of GSH and decrease SAHA-mediated apoptosis in CLL cells. Previous studies have demonstrated that HDACIs have limited activity in patients with CLL $(17,18)$. Since the bone marrow is an important site for malignant cells, a co-culture system using a bone marrow stromal cell line and primary leukemia cells isolated from patients with CLL was used to investigate the effect of bone marrow stromal cells and redox change on the activity of SAHA in CLL cells. As shown in Fig. 1A, the HS5 bone marrow stromal cells significantly reduced spontaneous CLL cell death. Incubation with $2 \mu \mathrm{M}$ SAHA for $48 \mathrm{~h}$ induced 60-70\% CLL cell death; however, HS5 cells markedly protected the CLL cells from SAHA-induced cell death (50-80\% viable cells; Fig. $1 \mathrm{~A})$.

The activity of HDACIs is affected by the redox status of malignant cells $(11,12)$. GSH is the most abundant antioxidant buffer system, and may be upregulated by stromal cells in the CLL cell (8). The present study subsequently investigated the role of GSH in stromal-mediated protection against SAHA action in the CLL cells. CLL cells cultured alone exhibited a time-dependent decrease in levels of GSH, whereas the addition of HS5 cells or supplementation with GSH precursor NAC maintained high intracellular levels of GSH in the CLL cells (Fig. 1B). On day 3, the stromal cells and NAC maintained the levels of GSH in the CLL cells in the range of 1.5-2 nmol $/ 1 \times 10^{7}$ cells, whereas single-cultured CLL cells without NAC supplementation had $<0.5 \mathrm{nmol} / 1 \times 10^{7}$ cells (Fig. 1B). Similar to the HS5 cells, supplementation of $1 \mathrm{mM}$ NAC in the CLL cell culture medium enhanced CLL cell viability for 7 days (Fig. 1C). The Annexin V/PI assay further determined that CLL cells in the presence of HS5 cells or NAC were 90-92\% viable, compared with the CLL cells cultured alone with low levels of GSH, of which only $22 \%$ were viable following 7 days incubation in vitro (Fig. 1D). Notably, incubation with $2 \mu \mathrm{M}$ SAHA for a further 2 days caused extensive apoptosis in the CLL cells alone (95\%), whereas the NAC or HS5 cells conferred significant protection to the CLL cells against SAHA, leading to 52 and $45 \%$ apoptotic cell death, respectively (Fig. 1D). Furthermore, the use of PEITC to rapidly deplete cellular GSH inhibited stromal protection of the CLL cells against SAHA toxicity, and enhanced the cytotoxic effects of SAHA in the presence of stromal cells (Fig. 1E). These results suggested that the bone marrow stromal cells protected the CLL cells from spontaneous and 
A

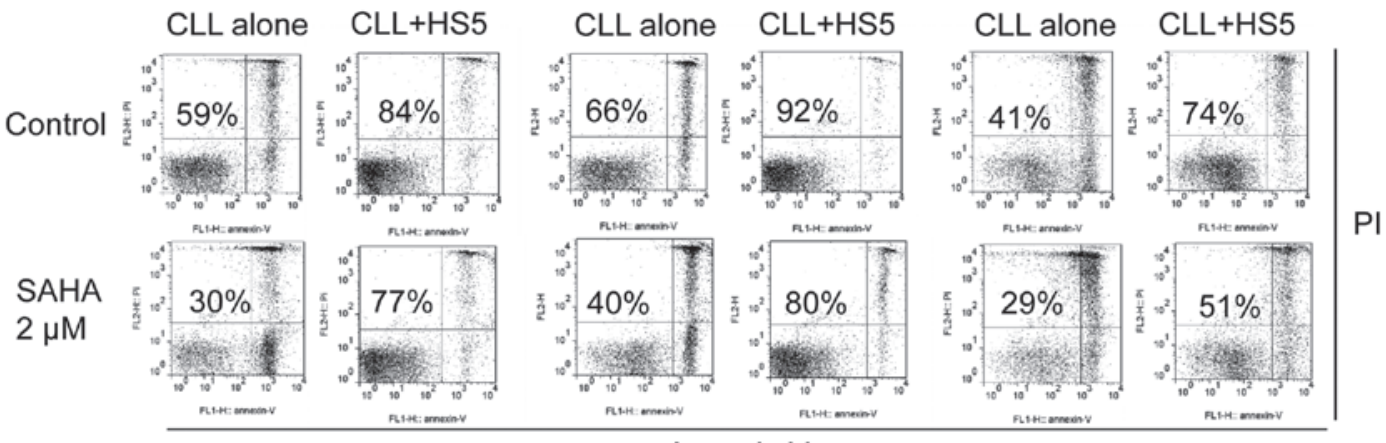

Annexin V

B

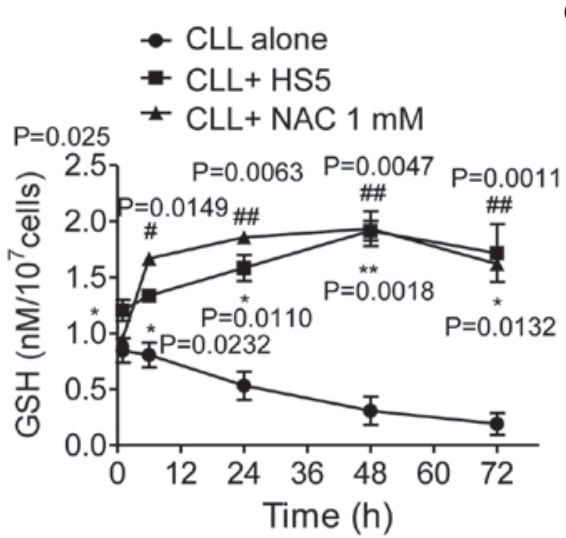

D

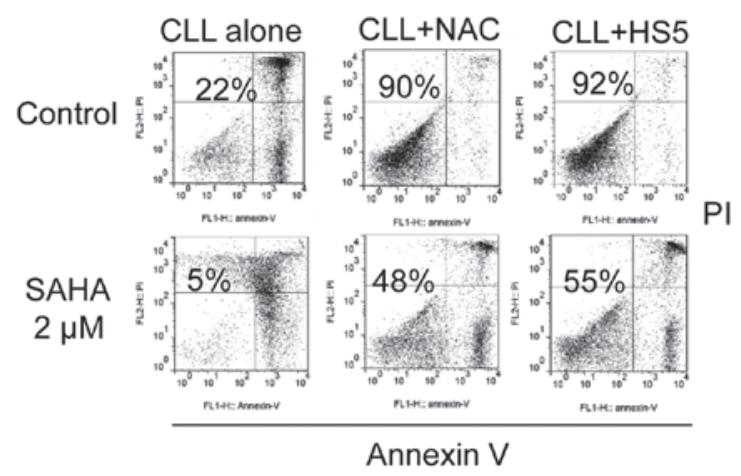

C

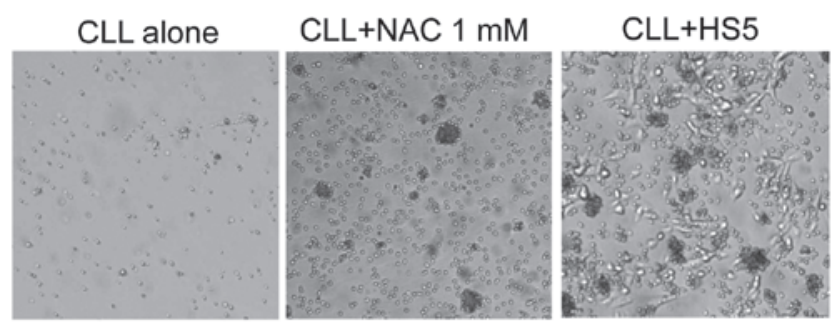

$\mathbf{E}$

CLL

CLL

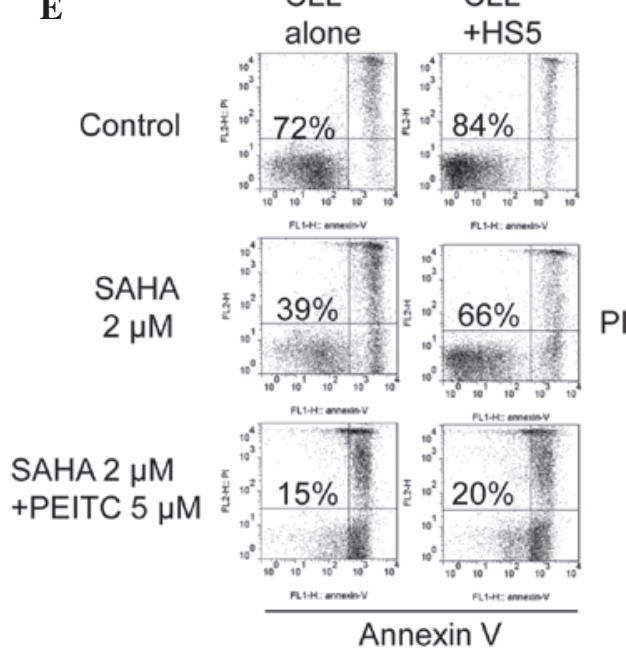

$+\mathrm{HS} 5$

Figure 1. GSH-mediated stromal protection of CLL cells from SAHA-induced cell death. (A) Protection of CLL cells by HS5 cells in the presence and absence of SAHA. The CLL cells were pre-cultured with HS5 cells for $24 \mathrm{~h}$, followed by $2 \mu \mathrm{M}$ SAHA incubation for $48 \mathrm{~h}$. Cell viability was measured using Annexin V/PI double staining. Representative dot plots of a CLL sample are shown, with numbers indicating the percentage of viable cells (Annexin V/PI double negative). (B) GSH levels over time in CLL cells cultured alone, with HS5 cells, or with NAC (1 mM). Values are presented as the mean \pm standard error of the mean of three separate experiments using three CLL samples ${ }^{*} \mathrm{P}<0.05$ and ${ }^{* * *} \mathrm{P}<0.01$, CLL cells cultured alone, vs. CLL cells cultured with HS5 cells; ${ }^{~} \mathrm{P}<0.05$ and ${ }^{\# \#} \mathrm{P}<0.01$, CLL cells cultured alone, vs. CLL cells cultured with NAC. (C) NAC and HS5 cells promoted CLL cell survival for 7 days. When stromal cells reached confluence, the CLL cells were transferred to a new flask pre-seeded with HS5 cells. Images were captured on day 7. (D) NAC and HS5 cells promoted CLL cell survival in the presence and absence of SAHA. The CLL cells were pre-cultured with HS5 cells or supplemented with NAC (1 mM) for 7 days, followed by $2 \mu \mathrm{M}$ SAHA incubation for $48 \mathrm{~h}$. Cell viability was measured using Annexin V/PI double staining. The number in each dot blot indicates the percentage of viable cells. (E) Annexin V/PI assay of cell viability following CLL cell culture alone or with HS5 cells, in the presence or absence of SAHA $(2 \mu \mathrm{M} ; 48 \mathrm{~h})$, or its combination with PEITC $(5 \mu \mathrm{M} ; 5 \mathrm{~h})$. The number in each dot blot indicates the percentage of viable cells. CLL, chronic lymphocytic leukemia; SAHA, suberoylanilide hydroxamic acid; GSH, glutathione; PI, propidium iodide; PEITC, $\beta$-phenylethyl isothiocyanate; NAC, N-acetylcysteine.

SAHA-induced apoptosis, and GSH was critical in the stromal protection of CLL cells against SAHA toxicity.

Bone marrow stromal cells reverse SAHA-induced ROS damage to mitochondria. Concordant with previous reports of ROS induction by HDACIs $(11,25)$, SAHA induced ROS generation in the CLL cells following $20 \mathrm{~h}$ of incubation (Fig. 2A). As CLL cells deplete GSH rapidly and rely on stromal cells to maintain intracellular GSH levels (8), the present study hypothesized that GSH deletion and SAHA-induced ROS generation cause a rapid redox imbalance and ROS-mediated mitochondrial damage, whereas bone marrow stromal cells 
A

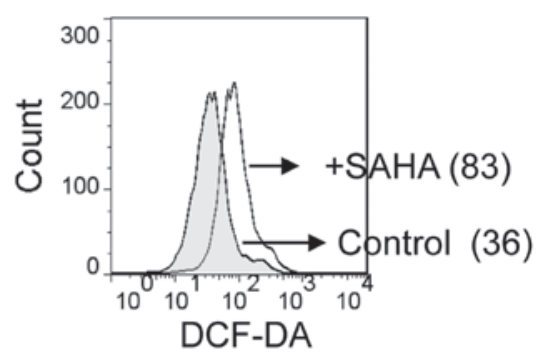

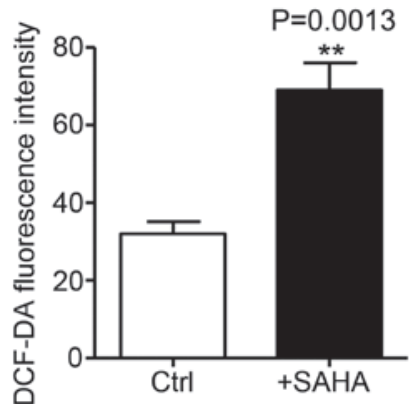

B
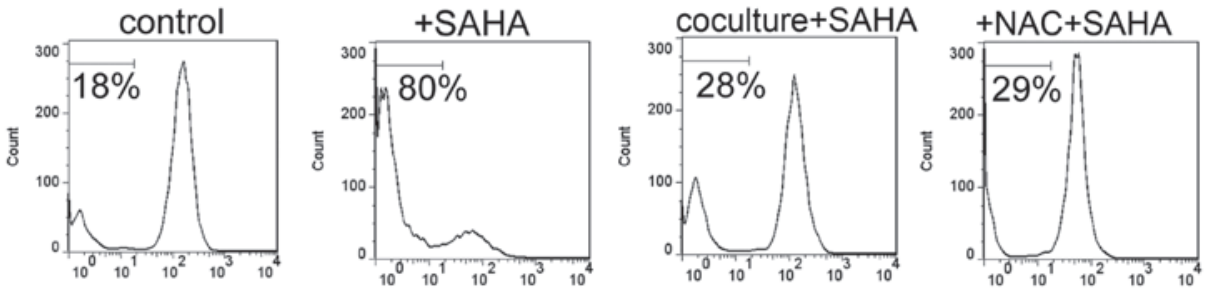

NAO

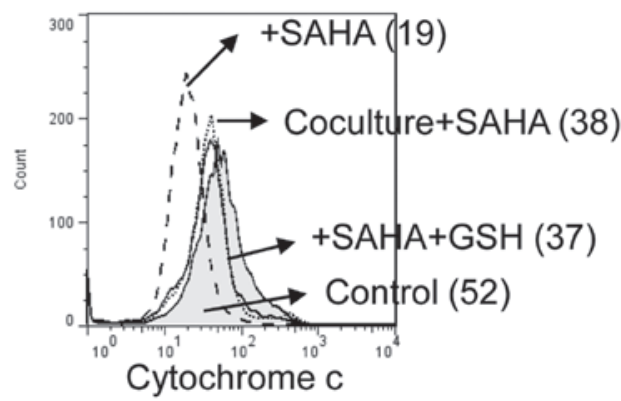

D
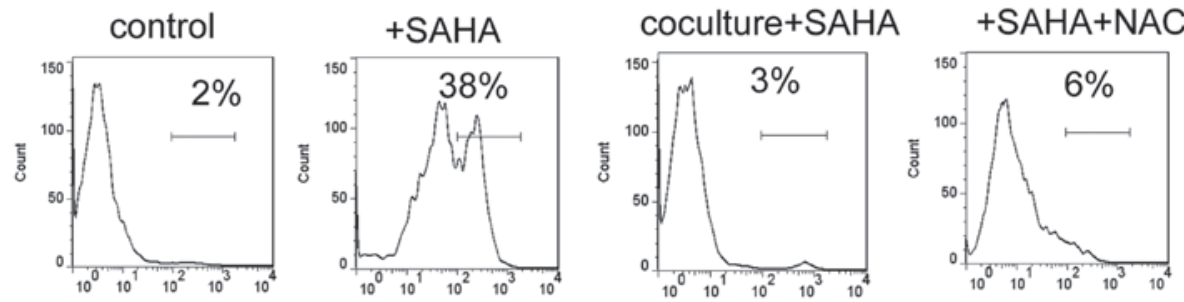

Caspase 3

Figure 2. Bone marrow stromal cells reverse SAHA-induced ROS damage to mitochondria. (A) Determination of cellular ROS in CLL cells with or without SAHA $(2 \mu \mathrm{M}, 20 \mathrm{~h})$ incubation, determined using flow cytometric analysis. A representative plot (left, mean value of relative intensity indicated) and quantitative comparison of the mean values \pm standard deviation from five CLL samples are shown (right, ${ }^{* *} \mathrm{P}<0.01$, vs. control). (B) Change of cardiolipin oxidation in CLL cells treated with SAHA at the indicated conditions. CLL cells were pre-cultured with HS5 cells or supplemented with NAC (1 mM) for $24 \mathrm{~h}$, followed by $2 \mu \mathrm{M}$ SAHA incubation for $22 \mathrm{~h}$. Cardiolipin oxidation was measured by flow cytometry using NAO staining. Representative histograms are shown. The numbers indicate the gating of the subpopulation of CLL cells exhibiting loss of cardiolipin signal due to oxidation. (C) Determination of mitochondrial cytochrome $c$ in CLL cells pre-cultured with HS5 cells or supplemented with NAC (1 mM) for $24 \mathrm{~h}$, followed by $2 \mu \mathrm{M}$ SAHA incubation for $24 \mathrm{~h}$. The overlays show the distribution of mitochondrial cytochrome $c$ fluorescence intensity of each cell population, with the mean value of the relative intensity indicated. Representative histograms of a CLL patient sample are shown. (D) Caspase 3 activation in CLL cells pre-cultured with HS5 cells or supplemented with NAC $(1 \mathrm{mM})$ for $24 \mathrm{~h}$, followed by $2 \mu \mathrm{M}$ SAHA incubation for $24 \mathrm{~h}$. The numbers indicate the gating of a subpopulation of cells with positive caspase 3 activation. Representative histograms of three separate experiments are shown. CLL, chronic lymphocytic leukemia; SAHA, suberoylanilide hydroxamic acid; ROS, reactive oxygen species; NAC, $\mathrm{N}$-acetylcysteine.

upregulate GSH and reverse SAHA-induced damage. As shown in Fig. 2B, incubation of the CLL cells with SAHA led to the rapid oxidation of cardiolipin, determined by the loss of interaction with fluorescent NAO dye. The NAO fluorescent signal increased between 18 and $80 \%$ following treatment with $2 \mu \mathrm{M}$ SAHA at $22 \mathrm{~h}$ (Fig. 2B). Notably, the HS5 cell or NAC-induced increase in intracellular levels of GSH in the CLL cells largely reduced the SAHA-induced loss of NAO signal between 80, and 28 and 29\%, respectively (Fig. 2B). A previous study demonstrated that cardiolipin induces 
A

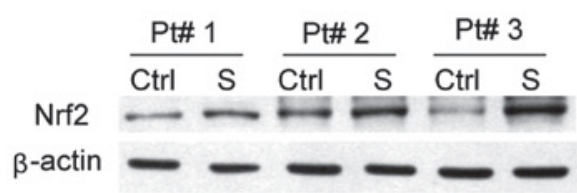

C

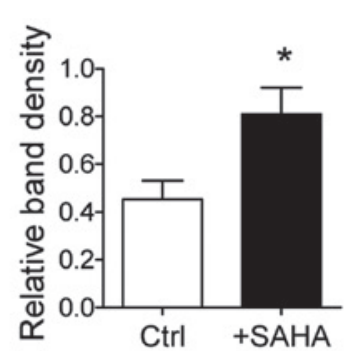

B
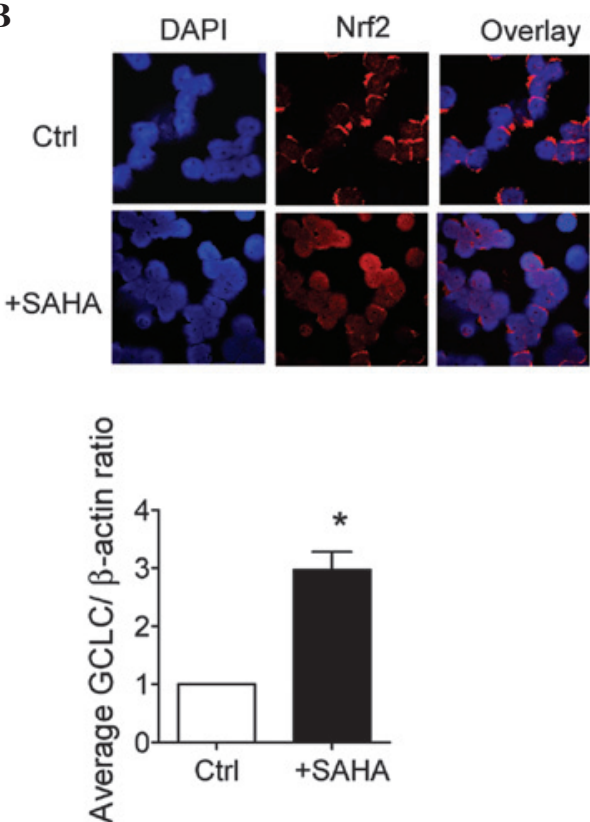

\section{D}

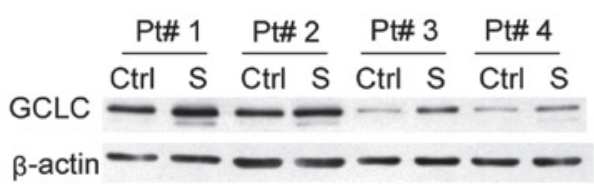

$\mathbf{E}$

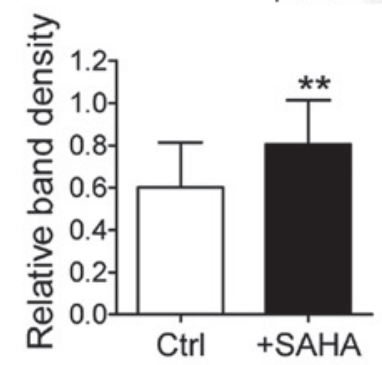

$\mathbf{F}$
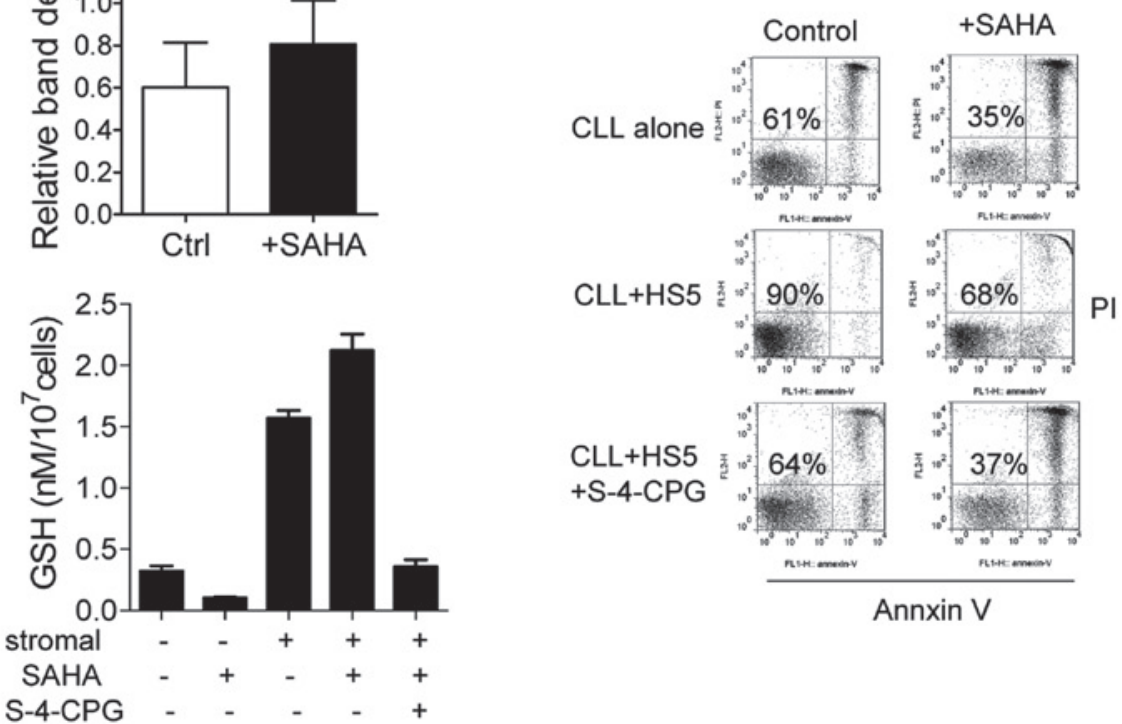

Figure 3. Effect of SAHA on levels of GSH-associated enzyme and GSH in CLL cells co-cultured with stromal cells. (A) SAHA increased the expression of Nrf2 in CLL cells. CLL cells were treated with $2 \mu \mathrm{M}$ SAHA for $20 \mathrm{~h}$, and cell lysates were assayed for Nrf 2 using western blot analysis. Representative western blot results from three samples from patients with CLL are shown. The right panel shows the quantification of Nrf2 band density of eight CLL samples, with $\beta$-actin expression as an internal control (mean \pm standard deviation; ${ }^{2} \mathrm{P}<0.05$; Ctrl, control cells without treatment; S, SAHA treatment). (B) SAHA induced the translocation of Nrf2 between the cytosol and nucleus. SAHA $(2 \mu \mathrm{M})$ was added to the CLL cells for $20 \mathrm{~h}$, and the cells were cytospun and immunostained with Nrf2 antibodies, and observed using a confocal laser scanning microscope. The nuclei were stained with 4,6-diamidino-2-phenylindole. (C) Upregulation of mRNA expression of GCLC following SAHA treatment. CLL cells were treated with $2 \mu$ M SAHA for $22 \mathrm{~h}$ and the GCLC mRNA expression was examined using reverse transcription-quantitative polymerase chain reaction. (D) SAHA increases the expression of GCLC in CLL cells. CLL cells were treated with $2 \mu \mathrm{M}$ SAHA for $24 \mathrm{~h}$, and the cell lysates were then assayed for the expression levels of GCLC by western blot analysis. The upper panel shows the representative western blot results from samples of four patients with CLL. The lower panel shows the quantification of GCLC band density of eight CLL samples, with $\beta$-actin as the internal control (mean \pm standard deviation; ${ }^{* *} \mathrm{P}<0.01$. (E) Treatment with SAHA enhanced stromal-mediated GSH upregulation in CLL cells. The CLL cells were treated with $2 \mu \mathrm{M}$ SAHA for $48 \mathrm{~h}$ in the presence or absence of HS5 cells. In another treatment group, CLL and HS5 cells in co-culture were incubated with cystine transporter inhibitor S-4-CPG $(500 \mu \mathrm{M})$ for $24 \mathrm{~h}$, then exposed to SAHA $(2 \mu \mathrm{M})$ for $48 \mathrm{~h}$. Values are presented as the mean \pm standard deviation of three independent experiments using three CLL samples. (F) Sensitization of CLL cells to SAHA by inhibiting the cystine transporter with S-4-CPG. CLL and HS5 cells in co-culture were incubated with S-4-CPG $(500 \mu \mathrm{M})$ for 24 h, then exposed to SAHA $(2 \mu \mathrm{M})$ for 48 h. Cell viability was analyzed using an Annexin V/PI assay. Representative dot plots are shown. CLL, chronic lymphocytic leukemia; SAHA, suberoylanilide hydroxamic acid; GSH, glutathione; PI, propidium iodide; Nrf2, nuclear factor-E2-related factor 2; CPG, carboxyphenylglycine Ctrl, untreated control; S, SAHA treatment. 
A

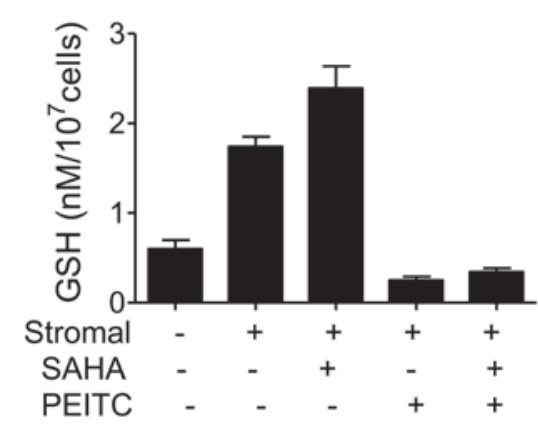

C

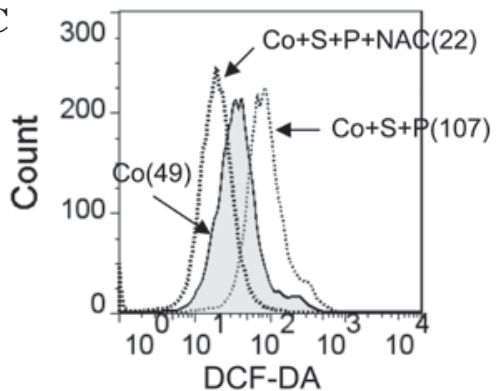

B

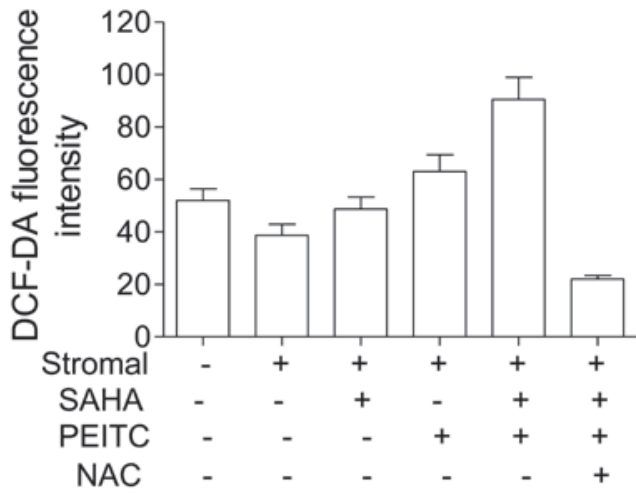

D

CLL+HS5

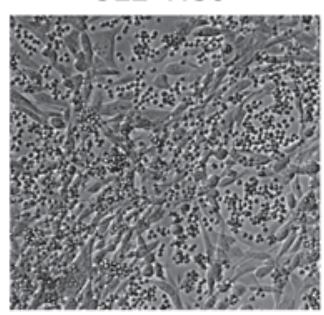

$\mathrm{CLL}+\mathrm{HS} 5+\mathrm{S}+\mathrm{P}$

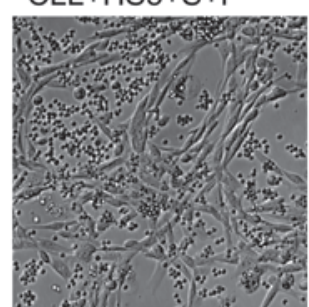

$\mathbf{E}$
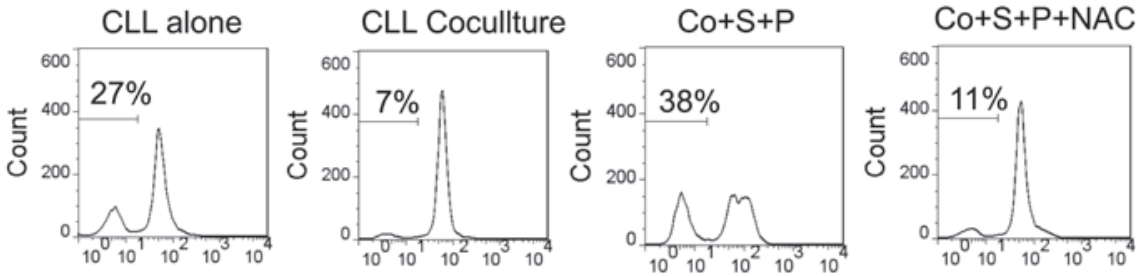

Rho-123

F

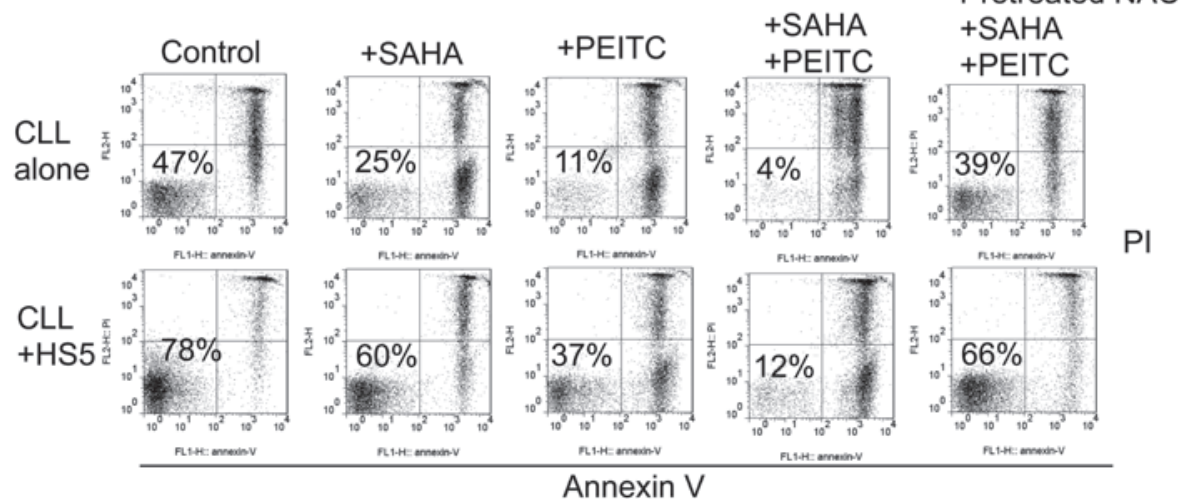

Figure 4. Treatment combination of PEITC and SAHA inhibits GSH upregulation in CLL cells, and induces ROS-mediated apoptosis. (A) Comparison of GSH levels in CLL cells treated with SAHA $(2 \mu \mathrm{M} ; 48 \mathrm{~h})$ or/and PEITC $(5 \mu \mathrm{M} ; 5 \mathrm{~h})$ in the presence of HS5 cells. The values are presented as the mean \pm standard deviation of three separate experiments using four CLL samples. (B) Determination of ROS levels in CLL cells treated with SAHA ( $2 \mu \mathrm{M} ; 48 \mathrm{~h})$ or/and PEITC $(5 \mu \mathrm{M} ; 5 \mathrm{~h})$ in the presence of HS5 cells, determined using flow cytometric analysis. Quantitative comparison of mean values \pm standard deviation from four CLL samples are shown. (C) Pre-treatment with NAC $(1 \mathrm{mM})$ blocked the upregulation of ROS induced by the combination of SAHA $(2 \mu \mathrm{M} ; 48 \mathrm{~h})$ and PEITC $(5 \mu \mathrm{M} ; 5 \mathrm{~h})$. The overlays show the distribution of ROS fluorescence intensity of each cell population, with the mean value of the relative intensity indicated. Representative histograms of a CLL patient sample are shown. (D) Combination of SAHA ( $\mu \mathrm{M} ; 48 \mathrm{~h})$ and PEITC $(5 \mu \mathrm{M} ; 5 \mathrm{~h})$ selectively eliminated CLL cells, sparing HS5 cells. Images of the cells were captured using a Nikon Eclipse TE2000 microscope. (E) Determination of mitochondrial transmembrane potential in CLL cells pre-cultured with HS5 cells or supplemented with NAC (1 mM) for $24 \mathrm{~h}$ followed by the co-administration of SAHA and PEITC. The numbers indicate the gating of the subpopulation of cells with loss of transmembrane potential. (F) Apoptosis induced by SAHA ( $2 \mu \mathrm{M} ; 48 \mathrm{~h})$ or/and PEITC $(5 \mu \mathrm{M} ; 5 \mathrm{~h})$ with or without HS5 cell co-culture was inhibited by pre-treatment with NAC $(1 \mathrm{mM})$. Representative dot plots of a CLL sample are shown; the numbers indicate the percentage of viable cells (Annexin V/PI double negative). CLL, chronic lymphocytic leukemia; SAHA, suberoylanilide hydroxamic acid; GSH, glutathione; PEITC, $\beta$-phenylethyl isothiocyanate; NAC, N-acetylcysteine; Co, co-culture; S, SAHA treatment; P, PEITC treatment; ROS, reactive oxygen species; PI, propidium iodide.

cytochrome $c$ release and caspase activation (21). As shown in Fig. $2 \mathrm{C}$ and $\mathrm{D}$, exposure to $2 \mu \mathrm{M}$ SAHA for $24 \mathrm{~h}$ induced mitochondrial cytochrome $c$ release and caspase 3 activation.
The HS5 cells and NAC also prevented SAHA-induced cytochrome $c$ release, and reduced caspase activation between 38 , and 3 and $6 \%$, respectively (Fig. $2 \mathrm{C}$ and D). These results 
A

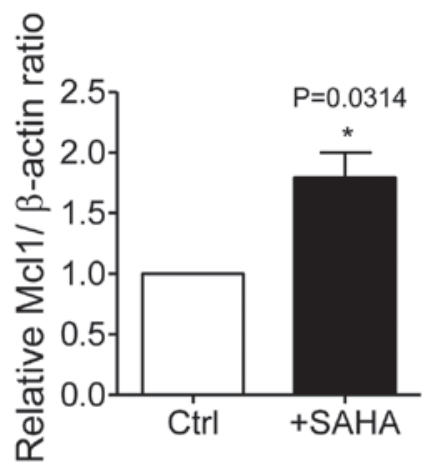

B

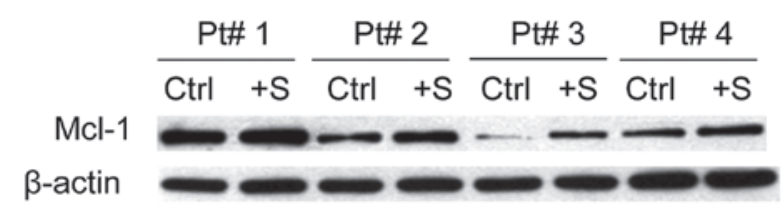

C

$\frac{\mathrm{Pt} \# 1}{\frac{-S A H A}{S C N} \frac{P t \# 2}{S C N} \frac{-S A H A}{S C N} \frac{+S A H A}{S C N}}$
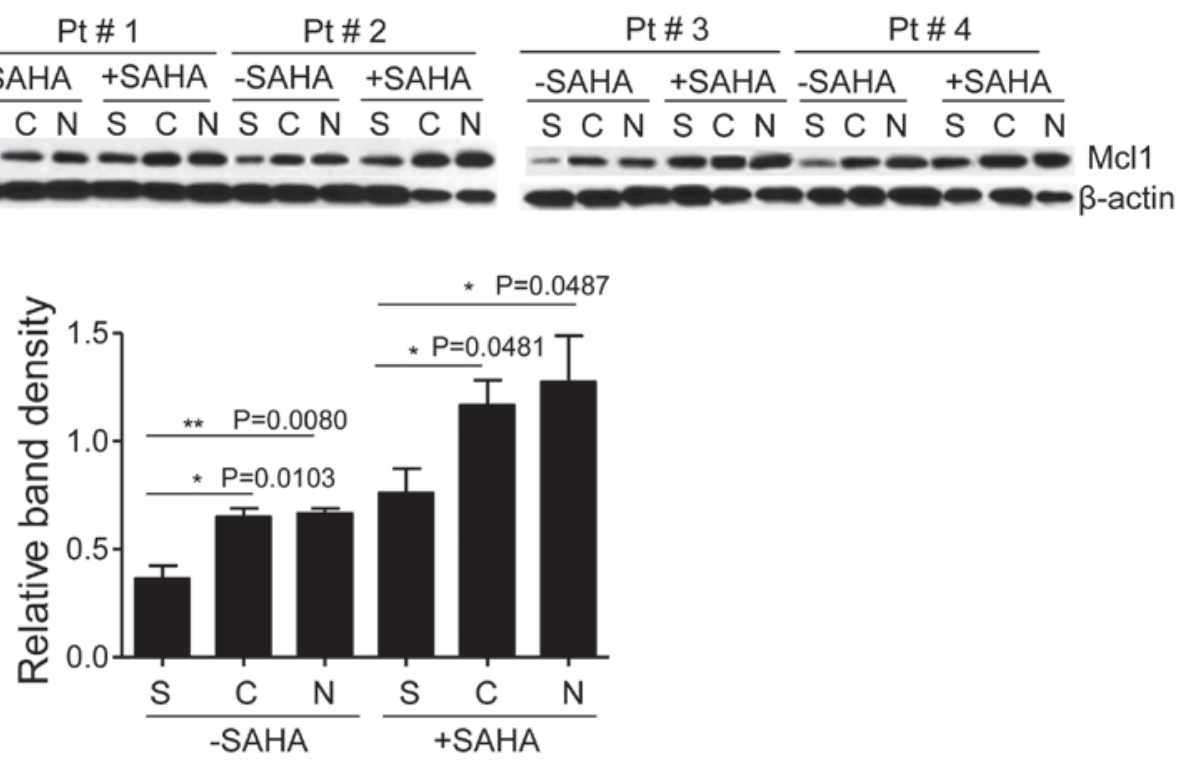

D

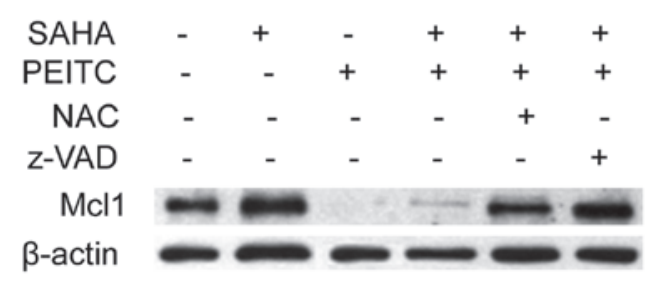

Pt\#1

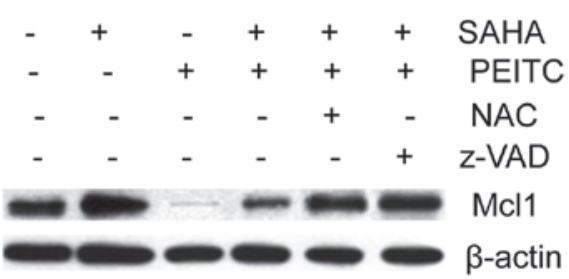

$\mathrm{Pt} 2$

$+\mathrm{HS} 5$

Figure 5. PEITC induces degradation of stromal cell and SAHA treatment-upregulated Mcl1 in CLL cells. (A) Upregulation of the mRNA expression levels of Mcl1 following SAHA treatment. CLL cells were treated with $2 \mu \mathrm{M}$ SAHA for $48 \mathrm{~h}$ and mRNA expression levels of Mcl1 were examined using reverse transcription-quantitative polymerase chain reaction analysis. (B) SAHA increased the protein expression of Mcl1 in CLL cells. CLL cells were treated with $2 \mu \mathrm{M}$ SAHA for $48 \mathrm{~h}$, and cell lysates were then assayed for expression of Mcl1 using western blot analysis. The panel shows the representative western blots of four samples of patients with CLL. (C) Expression levels of Mcl1 in CLL cells co-cultured with HS5 cells or supplemented with 1 mM NAC with or without SAHA treatment ( $2 \mu \mathrm{M} ; 48 \mathrm{~h})$. The upper panel shows the representative western blots of four samples of patients with CLL. The lower panel shows the quantification of Mcll band density, using $\beta$-actin as an internal control (mean \pm standard deviation). (D) PEITC $(5 \mu \mathrm{M} ; 5 \mathrm{~h})$ decreased expression levels of Mcl1 in CLL cells co-cultured with HS5 cells with or without SAHA treatment. NAC or caspase inhibitor (Z-VAD-fmk) suppressed PEITC-induced Mcl1 degradation. CLL cells were pretreated with $1 \mathrm{mM} \mathrm{NAC}$ for $24 \mathrm{~h}$ or $20 \mu \mathrm{M} \mathrm{Z-VAD-fmk} \mathrm{for} 30 \mathrm{~min}$ prior to treatment with PEITC. A representative western blot from experiments with two CLL samples is shown. CLL, chronic lymphocytic leukemia; SAHA, suberoylanilide hydroxamic acid; PEITC, $\beta$-phenylethyl isothiocyanate; NAC, N-acetylcysteine; Mcl1, myeloid cell leukemia 1; Ctrl, untreated control cells; +S, SAHA treatment; S, single culture of CLL cells alone; C, co-cultured with stromal cells; $\mathrm{N}$, supplemented with NAC.

suggested that bone marrow stromal cells, which increased the levels of intracellullar GSH in the CLL cells, reversed SAHA-induced ROS damage to the mitochondria in a similar manner to that by the NAC GSH precursor.

SAHA increases GSH synthesis, potentiates stromal-mediated GSH upregulation in CLL cells and protects cells from
SAHA-mediated ROS damage and apoptosis. A previous study suggested that the antioxidant system emerged to protect leukemia cells during cellular selection with HDACI (12). The present study investigated whether SAHA-induced ROS generation in CLL cells stimulated the compensatory antioxidant system. The NF-E2-related factor 2 (Nrf2) antioxidant response signaling pathway is the primary cellular defense mechanism 
against the cytotoxic effects of oxidative stress (22). As shown in Fig. 3A, incubation with $2 \mu \mathrm{M}$ SAHA for $20 \mathrm{~h}$ upregulated the expression of Nrf2 in the CLL cells. It has been suggested that Nrf2 localizes to the cytoplasm to interact with Kelch-like ECH-associating protein 1 (Keap1) in the normal physiological state (26). The activity of the Nrf2 signaling system is dependent upon redox homeostasis in the cells, and modification of Keap1 by ROS leads to Nrf2 dissociation and translocation to the nucleus, leading to transactivation of its downstream target genes (27). The present study used immunofluorescence staining with confocal microscopy to identify the subcellular location of Nrf2 translocation. Nrf2, revealed using Alexa Fluor ${ }^{\circledR} 594$ (in red) induced a condensed, ring-like staining pattern in the cytoplasm around the nucleus in untreated CLL cells (Fig. 3B). However, treatment with $2 \mu \mathrm{M}$ SAHA for $20 \mathrm{~h}$ resulted in an accumulation of $\mathrm{Nrf} 2$ within the nucleus, which was stained by DAPI, a DNA binding dye (Fig. 3B). These results suggested that SAHA induced Nrf2 translocation between the cytoplasm and nucleus in the CLL cells.

The expression of GCLC, a rate-limiting enzyme in GSH synthesis, is controlled by the Nrf2 transcription factor (28). In the present study, the mRNA expression levels of GCLC were examined. As shown in Fig. 3C, GCLC gene expression was upregulated in CLL cells following treatment with $2 \mu \mathrm{M}$ SAHA for $22 \mathrm{~h}$. The protein expression levels of GCLC also increased following treatment with SAHA (Fig. 3D). As determined by measurement of cellular GSH levels, SAHA treatment decreased levels of GSH in the CLL cells (Fig. 3E). These results suggested that the increase in GSH enzyme synthesis induced by SAHA treatment failed to promote GSH synthesis in the CLL cells, which was entirely distinct from the results in other types of leukemia (12). However, in the presence of HS5 cells, SAHA treatment increased, rather than decreased, levels of GSH in the CLL cells (Fig. 3E). It has been suggested that GSH synthesis is limited by the cellular levels of its cysteine substrate (28). Our previous report demonstrated that bone marrow stromal cells effectively imported cystine by the Xc-transporter, and converted it to cysteine to supply CLL cells for GSH synthesis (8). As shown in Fig. 3E, the Xc-transporter inhibitor, S-4-CPG, prevented SAHA-mediated GSH upregulation in the co-cultured CLL cells. In addition, sub-toxic concentration levels of S-4-CPG $(500 \mu \mathrm{M})$ inhibited stromal cell protection and enhanced SAHA-induced cytotoxicity, to levels comparable to those observed in CLL cells without stromal protection (Fig. 3F). These results suggested that stromal-produced GSH substrate and SAHA-induced GSH synthesis enzyme may promote an increase in GSH in CLL cells, and protect cells from SAHA-mediated ROS damage and apoptosis.

Treatment with PEITC overcomes stromal protection of CLL cells against SAHA toxicity by inhibiting stromal and SAHA-mediated upregulation of GSH in CLL cells. PEITC is a compound known to conjugate with GSH, leading to the exporation and depletion of cellular GSH (23), which is considered to be an important mechanism underlying PEITC-induced ROS stress in cancer cells. As shown in Fig. 4A, the HS5 cells upregulated the levels of GSH in the CLL cells, and treatment with $2 \mu \mathrm{M}$ SAHA caused a further increase in GSH following $48 \mathrm{~h}$ of co-culture in the CLL cells. However, the addition of
$5 \mu \mathrm{M}$ PEITC for $5 \mathrm{~h}$ markedly decreased levels of GSH in the CLL cells. Cellular ROS levels in the CLL cells were then examined under various conditions. In Fig. 4B, flow cytometric analysis demonstrated that both $2 \mu \mathrm{M}$ SAHA and $5 \mu \mathrm{M}$ PEITC increased ROS levels in the CLL cells co-cultured with the HS5 cells. The combination of these two compounds resulted in the additive accumulation of ROS, which was reversed by pre-treatment with $1 \mathrm{mM}$ NAC (Fig. 4B and C). These data suggested that PEITC depleted stromal cell-upregulated GSH in the CLL cells, and mediated SAHA induced-ROS generation in the co-cultured CLL cells.

Based on the above results, the present study hypothesized that PEITC may circumvent stromal protection against SAHA-induced ROS attack, and maximize its antileukemic activity by depleting stromal cell-upregulated cellular GSH in CLL cells. As shown in Fig. 4E, CLL cells alone exhibit 27\% loss of transmemebrane potential due to endogenous oxidative stress and spontaneous apoptosis, whereas HS5 stromal cells decreased CLL cell transmembrane potential loss to $7 \%$. Treatment with $2 \mu \mathrm{M}$ SAHA for $22 \mathrm{~h}$ followed by $5 \mu \mathrm{M}$ PEITC treatment for $5 \mathrm{~h}$ resulted in a $38 \%$ loss of transmembrane potential, indicating early induction of apoptosis. Notably, the effects of the combination were reversed by pre-teatment with $1 \mathrm{mM}$ NAC (Fig. 4E), indicating that accumulation of ROS in the CLL cells contributed to the cytotoxic effect induced by the combination of SAHA and PEITC.

The effect of the combination of SAHA and PEITC was also examined using an Annexin V/PI assay. As shown in Fig. 4F, incubation with $2 \mu \mathrm{M}$ SAHA for $48 \mathrm{~h}$ or $5 \mu \mathrm{M}$ PEITC for $5 \mathrm{~h}$ was toxic to single-cultured CLL cells, and HS5 cells protected the CLL cells from the cytotoxic effects of SAHA and PEITC. However, treatment with $2 \mu \mathrm{M}$ SAHA for $43 \mathrm{~h}$ followed by $5 \mu \mathrm{M}$ PEITC treatment for $5 \mathrm{~h}$ eliminated $>85 \%$ of the CLL cells with or without stromal protection. Concordantly, treatment with NAC largely inhibited the combination effects of SAHA and PEITC (Fig. 4F), which further confirmed that SAHA and PEITC combination led to ROS-mediated cell death. Furthermore, the combination of the two drugs eliminated the CLL cells cultured with HS5 cells, although the HS5 stromal layers were not visibly affected (Fig. 4D), indicating that the combination of SAHA and PEITC preferentially destroyed the CLL cells co-cultured with stromal cells, but spared the normal stromal cells.

PEITC induces rapid degradation of stromal cell and SAHA treatment-upregulated Mcll in CLL cells. Anti-apoptotic proteins, including B-cell lymphoma $(\mathrm{Bcl})-2$ and $\mathrm{Mcl} 1$ are important in cancer cell survival. Unlike Bcl-2, Mcl1 has a short half-life and its expression is tightly regulated by survival and apoptotic signals (29). In CLL cells, Mcl1 is particularly important in microenvironment-mediated survival and drug resistance (30). Treatment with $5 \mu \mathrm{M}$ SAHA for $48 \mathrm{~h}$ caused an increase in the mRNA expression of Mcl1 in the CLL cells (Fig. 5A). The protein expression levels of Mcl1 in the CLL cells were also increased following treatment with SAHA (Fig. 5B), indicating that SAHA upregulated the expression of Mcl1 in the CLL cells. In addition, co-culture with HS5 cells or treatment with NAC significantly increased the levels of Mcl1 in the CLL cells (Fig. 5C). Mcl1 has been demonstrated to be stabilized by GSH via glutathionylation (23). It is likely 


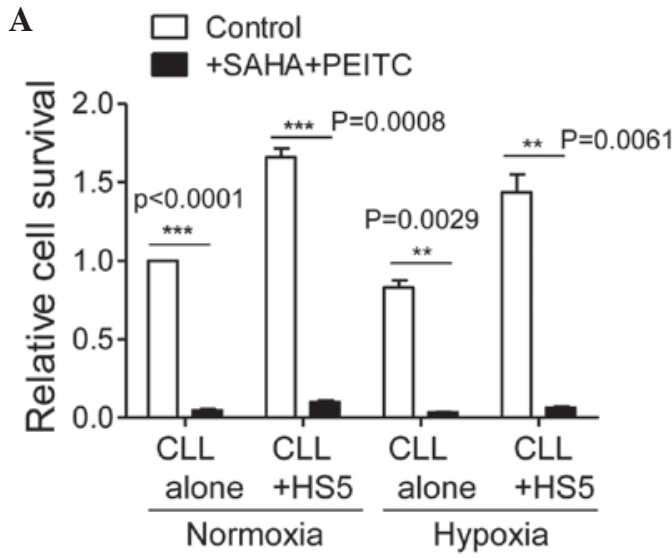

B

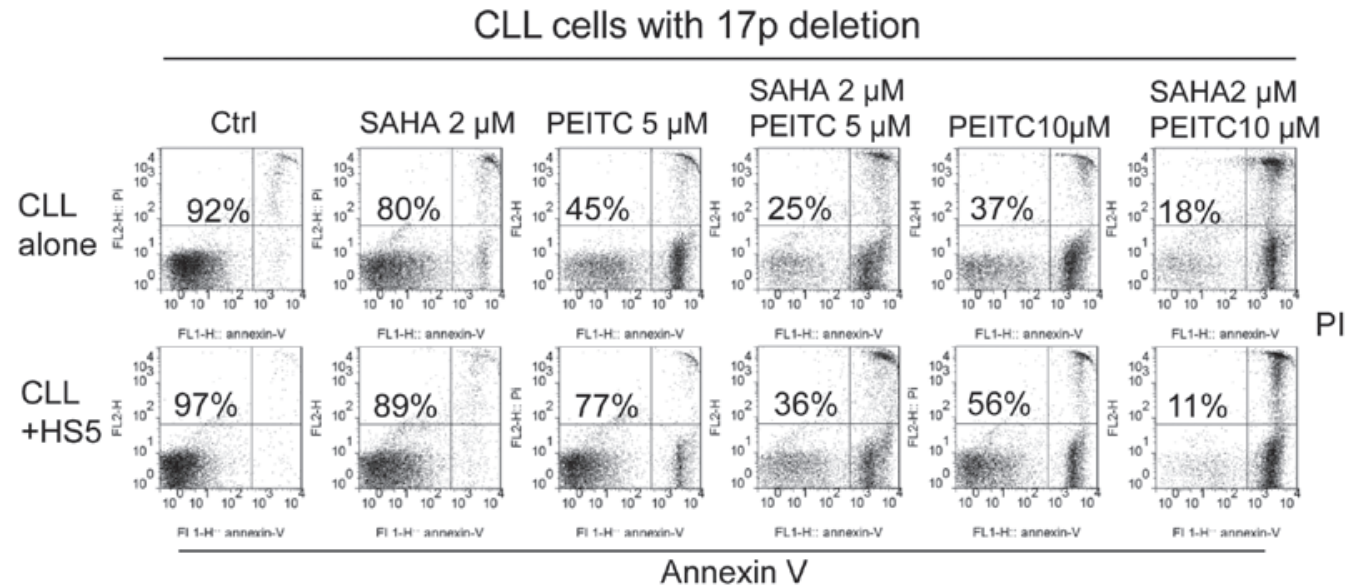

Figure 6. Overcoming stromal protection of CLL cells using the treatment combination of SAHA and PEITC. (A) Effects of combination of SAHA and PEITC on CLL cells with or without HS5 cells in normoxic and hypoxic conditions. CLL cells with or without HS5 cells were exposed to SAHA ( $\mu$ M) for $48 \mathrm{~h}$ under normoxic $(21 \%)$ or hypoxic $(2 \%)$ conditions. PEITC $(5 \mu \mathrm{M})$ was added during the last $5 \mathrm{~h}$ of incubation. Cell viability was analyzed using an Annexin V/propidium iodide assay. The data are presented as the mean \pm standard deviation of viable cells (\%) from four samples of patients with CLL. (B) Effects of treatment with SAHA, PEITC, and their combination on a CLL sample with chromosome 17p deletion. CLL cells with or without HS5 were exposed to various concentrations of PEITC $(5$ or $10 \mu \mathrm{M} ; 5 \mathrm{~h})$ and SAHA $(2 \mu \mathrm{M} ; 48 \mathrm{~h})$ alone, or in combination. PEITC was added during the last $5 \mathrm{~h}$ of incubation. The percentages indicate the percentage of viable cells. CLL, chronic lymphocytic leukemia; SAHA, suberoylanilide hydroxamic acid; PEITC, $\beta$-phenylethyl isothiocyanate; PI, propidium iodide; Ctrl, untreated control.

that stromal cells stabilize Mcl1 in CLL cells by upregulating GSH levels, thereby promoting glutathionylation of Mcl1. When the CLL cells co-cultured with HS5 cells or pre-treated with NAC were incubated with $5 \mu \mathrm{M}$ SAHA for $48 \mathrm{~h}$, a 3 -fold increase in the levels of Mcll were observed, compared with the CLL cells cultured alone or without NAC (Fig. 5C). These data suggested that the levels of Mcl1 in the CLL cells were increased in the presence of bone marrow stromal cells, and were further enhanced by SAHA treatment.

Due to the fact that PEITC depletes GSH and causes protein deglutathionylation, including Mcl1 (23), the present study hypothesized that PEITC may cause degradation of Mcl1 and circumvent stromal cell and SAHA-mediated Mcl1 upregulation in CLL cells. To investigate this possibility, the expression of Mcl1 was examined in CLL cells treated with the combination of SAHA and PEITC in the presence of HS5 cells. As shown in Fig. 5D, SAHA incubation increased the expression of Mcl1 in the CLL cells co-cultured with HS5 cells, however, PEITC substantially abrogated the expression of Mcl1 upregulated by SAHA treatment in the CLL cells. Treatment with NAC to replenish GSH levels significantly prevented the PEITC-mediated decrease in the levels of Mcl1. Notably, the caspase inhibitor, Z-VAD.fmk, inhibited PEITC-induced Mcl1 degradation (Fig. 5D), indicating that caspase was the major protease cleaved by Mcl1 following treatment with PEITC. These results suggested that stromal cells and SAHA treatment upregulated the expression of Mcl1 in the CLL cells, however, PEITC induced deglutathionylation of Mcl1 followed by caspase cleavage and degradation, which likely potentiated HDACI-mediated apoptosis in the CLL cells co-cultured with the stromal cells.

Combination treatment with SAHA and PEITC effectively eliminates CLL cells in the presence of bone marrow stromal cells. Annexin V/PI staining was used to examine the effects of SAHA, PEITC, and their combination on primary CLL 
cells from multiple patients cultured on stromal layers. Fresh CLL cells isolated from 10 patients with CLL were co-cultured with HS5 cells and treated with $2 \mu \mathrm{M}$ SAHA alone for $48 \mathrm{~h}$, $5 \mu \mathrm{M}$ PEITC alone for $5 \mathrm{~h}$, or the combination of $2 \mu \mathrm{M}$ SAHA for $43 \mathrm{~h}$ followed by $5 \mu \mathrm{M}$ PEITC for $5 \mathrm{~h}$, respectively. As shown in Table I, SAHA alone caused $20-60 \%$ cell death in the co-cultured CLL cells isolated from different patient samples. PEITC was more toxic towards the CLL cells and caused $40-70 \%$ cell death in these samples. Notably, the combination of SAHA and PEITC caused $>80 \%$ loss of viability in the co-cultured CLL cells. These results indicated that the effect of the combination was more than an additive effect in all 10 patient samples, and the combination of PEITC and SAHA effectively destroyed the CLL cells co-cultured with the stromal cells.

Due to the hypoxic bone marrow environment, the effects of treatment combination of SAHA and PEITC in CLL cells cultured on a stromal layer in various oxygen condition was examined. As shown in Fig. 6A, bone marrow stromal cells enhanced CLL viability under ambient or hypoxic conditions. Concordantly, significant apoptotic cell death induced by the combination of $2 \mu \mathrm{M}$ SAHA and $5 \mu \mathrm{M}$ PEITC in the CLL cells was observed under ambient oxygen and hypoxic conditions, suggesting that co-administration of SAHA and PEITC may effectively eliminate CLL cells in the hypoxic bone marrow environment.

Clinical studies have demonstrated that the loss of p53 in CLL cells due to a chromosome 17p deletion is known to cause drug resistance and poor prognosis in patients with CLL $(1,23,31)$. As shown in Fig. 6B, primary CLL cells isolated from a patient with $17 \mathrm{p}$ deletion were highly resistant to SAHA treatment in the presence or absence of stromal cells. Compared with p53-positive CLL cells, which exhibited 30-60\% viability following PEITC treatment in the presence of HS5 cells (Table I), the p53-negative CLL cells co-cultured with HS5 cells exhibited $77 \%$ viability following treatment with $5 \mu \mathrm{M}$ PEITC for $5 \mathrm{~h}$ (Fig. 6B). The combination of $2 \mu \mathrm{M}$ SAHA and $5 \mu \mathrm{M}$ PEITC resulted in a higher than additive effect on cell death with or without HS5 cells. Notably, $10 \mu \mathrm{M}$ PEITC was able to eliminate $\sim 50 \%$ of the p53-negative CLL cells in the presence of HS5 cells, and was highly effective when combined with $2 \mu \mathrm{M}$ SAHA, resulting in $90 \%$ cell death (Fig. 6B). These data suggested that the combination of PEITC and SAHA was highly effective at eliminating CLL cells containing the $17 \mathrm{p}$ deletion in the presence of bone marrow stromal cells.

\section{Discussion}

CLL is characterized by the abnormal accumulation of functionally defective B lymphocytes in the blood, bone marrow, spleen and other organs, eventually leading to organ failure and ultimately the patient succumbing to the disease $(3,32)$. Cross-talk between CLL cells and bone marrow stromal cells favors CLL progression and drug resistance (8). Therefore, disrupting the interaction between CLL cells and their environment is an attractive, novel strategy for treating patients with CLL. Our previous study reported an important metabolic interaction between CLL cells and bone marrow stromal cells, which increased GSH synthesis and thus increased the ability of CLL cells to maintain the redox balance, promoting cell survival and drug resistance (8). It was demonstrated that the GSH depleting agent, PEITC, was effective at inhibiting stromal protection in CLL cells and enhancing drug sensitivity (10). The aims of the present study were to further evaluate this biochemical intervention strategy in CLL cells, and to develop a combined treatment strategy to overcome drug resistance and eliminate residual CLL cells.

HDACIs are a novel class of targeted anticancer agents (33). HDACIs have multiple biological effects, including histone and non-histone protein acetylation, apoptosis, cell cycle arrest and senescence (10). A previous study reported that HDACIs generate ROS in cancer cells (12). Multiple preclinical studies and clinical data support the use of HDACI in combination with other drugs for the treatment of various types of cancers $(12,34,35)$. SAHA is a small molecule inhibitor of class I and II HDACs, and preclinical data has suggested a role for SAHA as a potential novel treatment in several tumor types, including hematological malignancies $(36,37)$. SAHA has been approved for use against cutaneous T cell lymphoma (38). However, the activity of SAHA has been modest in patients with leukemia (39). In patients with CLL, initial monotherapy clinical trials with various HDACIs revealed limited activity of the drug $(17,18)$. The present study demonstrated that bone marrow stromal cells protected CLL cells against SAHA cytotoxicity, indicating that bone marrow stromal cells may affect SAHA sensitivity in patients with leukemia. Notably, combined treatment with SAHA and PEITC induced extensive apoptosis in the CLL cells in the presence of stromal cells. Flow cytometric analysis following Annexin V/PI staining revealed that the effect of the combination of drugs was more than additive in the CLL cells from multiple patient samples co-cultured with stromal cells. These results indicated that a greater level of efficacy was achieved with combined treatment of SAHA and PEITC.

A previous study suggested that ROS are important in the action of SAHA in acute myeloid leukemia cells, and that the cellular redox status regulates sensitivity to SAHA treatment (12). Previous studies using primary leukemia cells isolated from the blood samples of patients with CLL demonstrated that CLL cells are intrinsically under high oxidative stress, compared with normal lymphocytes (7), and are highly sensitive to agents that cause further $\operatorname{ROS}$ stress $(7,23)$. Therefore, CLL cells may have increased dependency on the GSH antioxidant system. The results of the present study suggested that single-cultured CLL cells exhibited low intracellular levels of GSH, and were sensitive to SAHA-mediated ROS attack; however, bone marrow stromal cells upregulated the expression of GSH in the CLL cells and protected the cells from SAHA-induced oxidative stress and apoptosis. The results further indicated that the GSH precursor, NAC, protected the CLL cells against SAHA treatment. These findings suggested that stromal cell-mediated GSH upregulation in CLL cells is important in drug resistance to SAHA.

PEITC is known to deplete GSH in single and co-cultured CLL cells $(8,23)$. The selective cytotoxic effect of PEITC against CLL cells also makes it a potential candidate for combination treatment with SAHA. The present study demonstrated that SAHA induced significant ROS generation in the CLL cells, followed by oxidative mitochondrial damage, 
cytochrome $c$ release and apoptosis, whereas stromal cells prevented SAHA-induced ROS damage and apoptosis in the CLL cells. The combination of SAHA and PEITC significantly increased cellular ROS accumulation and apoptotic cell death of the CLL cells in the presence of stromal cells. Treatment with antioxidant NAC effectively decreased ROS and apoptosis in the CLL cells following the combination treatment of SAHA and PEITC, indicating that the combined effect is mediated by ROS accumulation. Notably, although the combination of SAHA and PEITC destroyed CLL cells cultured with stromal cells, the stromal layer was intact following treatment, indicating that the combination had therapeutic selectivity. In addition, since CLL cells, which no longer express p53 are often resistant to chemotherapy and have poor clinical outcomes, the present study also examined the combination treatment strategy in CLL cells from p53-negative patients, and demonstrated that the p53-null CLL cells were resistant to SAHA treatment, even without stromal cells, consistent with the effects of p53 on drug sensitivity. However, these cells remained sensitive to PEITC, and the combination of $2 \mu \mathrm{M}$ SAHA and $10 \mu \mathrm{M}$ PEITC resulted in increased cell death in the p53-negative CLL cells co-cultured with stromal cells. The novel treatment combination strategy, which circumvents stromal protection and eliminates CLL cells including p53-negative CLL cells, has significant clinical effects.

A previous report demonstrated that SAHA induces the early increase of ROS through nicotinamide adenine dinucleotide phosphate oxidase in leukemia cells, which results in the translocation of Nrf2 between the cytosol and nucleus, leading to the upregulation of glutathione-associated enzymes as a cellular protective mechanism (12). The Nrf2 transcription factor controls the expression of GSH-generating enzymes, including GCLC, a rate-limiting enzyme in GSH synthesis (28). Nrf2 localizes to the cytoplasm in order to interact with Keap1, and oxidative modification of Keap1 causes the release and translocation of Nrf2 between the cytoplasm and nucleus, where it binds to antioxidant responsive elements (40). To investigate whether SAHA-induced ROS stress initiates the compensatory antioxidant system in CLL cells to maintain the redox balance, the present study examined the expression levels and activation of Nrf2 and GCLC in CLL cells following SAHA treatment. Confocal microscopic analysis demonstrated the translocation of Nrf2 between the cytoplasm and nucleus in the CLL cells following treatment with SAHA. The expression levels of Nrf2 and GCLC were also upregulated by SAHA incubation in the CLL cells. Notably, although Nrf2 activation and enhanced expression of GCLC has been reported to increase GSH levels in AML cells (12), the present study demonstrated that they failed to promote GSH synthesis in the CLL cells. These data indicated that the mechanism underlying the resistance to SAHA treatment is different in AML and CLL cells, and the compensatory antioxidant system activated by SAHA treatment fails to induce SAHA resistance in CLL cells cultured alone.

Cysteine is the rate-limiting substrate for GSH synthesis, and the predominant source of cysteine in cells is the uptake of extracellular cysteine or cystine through specific transporters (41). Our previous study suggested that CLL cells exhibit limited ability to transport cystine due to low expression levels of the Xc-cystine transporter, and rely on stromal cells to import cystine and convert it to cysteine, which is released into the microenvironment for the uptake by CLL cells to enhance GSH synthesis (8). The present study demonstrated that treatment with SAHA increased levels of GSH in the CLL cells only in the presence of stromal cells. It is likely that the increased expression of the GSH synthesis enzyme following SAHA incubation and the supplementation of cysteine by stromal cells cooperated to promote GSH synthesis in the CLL cells. Unlike CLL cells, the expression of GCLC and levels of GSH in AML cells increase following SAHA incubation without stromal cells (12), which may be due to the endogenous expression of Xc-, and thus self-sufficiency of cystine in AML cells. In CLL and AML cells, elevated GSH protects leukemia cells from SAHA-induced cytotoxicity, and disabling this protective mechanism using the GSH depleting agent, PEITC, significantly sensitizes CLL cells to SAHA treatment in the stromal environment.

The antiapoptotic protein, Mcl1, is critical in prolonging CLL cell survival, particularly in a tumor-stroma context (42). Previous studies have reported that a decrease in the expression of Mcl1 is essential for the induction of apoptosis by diverse stimuli $(43,44)$. However, instead of decreased expression of Mcl1, the present study observed an increase in Mcl1 following SAHA treatment in the CLL cells, which was concordant with a previous report that demonstrated that HDACIs induce apoptosis primarily via the Bcl-2-antagonist killer/Mcl1/Moxa and Bcl-2 interacting mediator of cell death signaling pathways, without decreasing the expression of Mcl1 (45). Furthermore, the present study demonstrated that bone marrow stromal cells or the GSH precursor, NAC, further increased the expression of Mcl1 in the CLL cells treated with SAHA. A previous study reported that protein glutathionylation regulates the functions of multiple proteins (46), and glutathionylation of Mcl1 regulates its stability (23). Since bone marrow stromal cells increased the levels of GSH in the CLL cells, the upregulated protein expression of Mcl1 in the CLL cells following SAHA treatment may be further glutathionylated and stabilized in a stromal environment.

Mcl1 is functionally important in leukemia cells, as marked potentiation of HDACI-induced apoptosis has been reported following the inhibition of Mcl1 by either cyclin-dependent kinase inhibitors or Mcl1 small interfering RNA in leukemia cells (45). Therefore, HDACI-mediated Mcl1 upregulation may have an important antiapoptotic role in limiting the efficacy of HDACI-induced apoptosis. In the present study, the results demonstrated that the GSH depleting agent, PEITC, suppressed the expression of Mcl1 through deglutathionylation, and circumvented drug resistance to SAHA treatment in the CLL cells co-cultured with stromal cells. A previous report demonstrated that the loss of p53 leads to the upregulation of Mcl1 through the downregulation of microRNA (miR)-15a and miR-16-1, and thereby contributes to drug resistance in p53-null CLL cells (47). In the present study, Mcl1 in the p53-null CLL cells was further increased by SAHA treatment in the presence of stromal cells, and induced marked drug resistance. Notably, compared with the p53-positive cells, the p53-negative CLL cells co-cultured with stromal cells were highly resistant to SAHA treatment. However, p53-positive and negative CLL 
cells exhibited high sensitivity to the combination of SAHA and PEITC treatment in the presence of stromal cells, which was partially due to the PEITC-mediated suppression of Mcl1 in the CLL cells.

In conclusion, the results of the present study demonstrated that bone marrow stromal cells upregulated the levels of GSH in CLL cells, and protected CLL cells against SAHA-induced oxidative stress and apoptosis. Notably, the present study demonstrated that the combination of a HDACI with the GSH depletion agent, PEITC, enabled the induction of high levels of CLL apoptosis, and overcame the protection of CLL cells by bone marrow stromal cells. The mechanism underlying the combination cytotoxicity involved disruption of the stroma-leukemia interaction through the GSH-mediated cytoprotective signaling pathway by PEITC, which significantly enhanced the anti-leukemic activity of HDACI. These results suggested that SAHA in combination with PEITC represents a promising treatment strategy to overcome microenvironment-mediated drug resistance and improve the treatment outcome in patients with CLL.

\section{Acknowledgements}

The present study was supported by the National Natural Science Foundation of China (grant no. 81201714), the Science Foundation of the Jiangxi Science and Technology Department (grant no. 20142BAB215043) and the Science Foundation of the Jiangxi Educational Committee (grant no. GJJ14173).

\section{References}

1. Keating, MJ, Chiorazzi, N, Messmer, B, Damle, RN, Allen, SL, Rai, KR, Ferrarini, M and Kipps, TJ: Biology and treatment of chronic lymphocytic leukemia. Hematology Am Soc Hematol Educ Program 2003, 153-175, 2003.

2. Tam CS and Keating MJ: Chemoimmunotherapy of chronic lymphocytic leukemia. Best Pract Res Clin Haematol 20 479-498, 2007.

3. Chiorazzi N, Rai KR and Ferrarini M: Chronic lymphocytic leukemia. N Engl J Med 352: 804-815, 2005.

4. Munk Pedersen I and Reed J: Microenvironmental interactions and survival of CLL B-cells. Leuk Lymphoma 45: 2365-2372, 2004.

5. Silber R, Farber CM, Papadopoulos E, Nevrla D, Liebes L, Bruck M, Brown R and Canellakis ZN: Glutathione depletion in chronic lymphocytic leukemia B lymphocytes. Blood 80: 2038-2043, 1992.

6. Collins RJ, Verschuer LA, Harmon BV, Prentice RL, Pope JH and Kerr JF: Spontaneous programmed death (apoptosis) of B-chronic lymphocytic leukaemia cells following their culture in vitro. Br J Haematol 71: 343-350, 1989.

7. Zhou Y, Hileman EO, Plunkett W, Keating MJ and Huang P: Free radical stress in chronic lymphocytic leukemia cells and its role in cellular sensitivity to ROS-generating anticancer agents. Blood 101: 4098-4104, 2003.

8. Zhang W, Trachootham D, Liu J, Chen G, Pelicano H, GarciaPrieto C, Lu W, Burger JA, Croce CM, Plunkett W, Keating MJ and Huang P: Stromal control of cystine metabolism promotes cancer cell survival in chronic lymphocytic leukaemia. Nat Cell Biol 14, 276-286, 2012.

9. Kelland L: The resurgence of platinum-based cancer chemotherapy. Nat Rev Cancer 7: 573-584, 2007.

10. Xu WS, Parmigiani RB and Marks PA: Histone deacetylase inhibitors: Molecular mechanisms of action. Oncogene 26: 5541-5552, 2007

11. Rosato RR, Almenara JA and Grant S: The histone deacetylase inhibitor MS-275 promotes differentiation or apoptosis in human leukemia cells through a process regulated by generation of reactive oxygen species and induction of p21CIP1/WAF1 1. Cancer Res 63: 3637-3645, 2003.
12. Hu Y, Lu W, Chen G, Zhang H, Jia Y, Wei Y, Yang H, Zhang W, Fiskus W, Bhalla $\mathrm{K}$, et al: Overcoming resistance to histone deacetylase inhibitors in human leukemia with the redox modulating compound $\beta$-phenylethyl isothiocyanate. Blood 116: 2732-2741, 2010

13. O'Connor OA, Heaney ML, Schwartz L, Richardson S, Willim R, MacGregor-Cortelli B, Curly T, Moskowitz C, Portlock C, Horwitz S, et al: Clinical experience with intravenous and oral formulations of the novel histone deacetylase inhibitor suberoylanilide hydroxamic acid in patients with advanced hematologic malignancies. J Clin Oncol 24: 166-173, 2006.

14. Stamatopoulos B, Meuleman N, De Bruyn C, Delforge A, Bron D and Lagneaux L: The histone deacetylase inhibitor suberoylanilide hydroxamic acid induces apoptosis, down-regulates the CXCR4 chemokine receptor and impairs migration of chronic lymphocytic leukemia cells. Haematologica 95, 1136-1143, 2010.

15. Pérez-Perarnau A, Coll-Mulet L, Rubio-Patiño C, Iglesias-Serret D, Cosialls AM, González-Gironès DM, de Frias M, de Sevilla AF, de la Banda E, Pons G and Gil J: Analysis of apoptosis regulatory genes altered by histone deacetylase inhibitors in chronic lymphocytic leukemia cells. Epigenetics 6: 1228-1235, 2011

16. Abou-Nassar, K. \& Brown, J.R. Novel agents for the treatment of chronic lymphocytic leukemia. Clin Adv Hematol Oncol 8, 886-895.

17. Blum KA, Advani A, Fernandez L, Van Der Jagt R, Brandwein J, Kambhampati S, Kassis J, Davis M, Bonfils C, Dubay M, et al: Phase II study of the histone deacetylase inhibitor MGCD0103 in patients with previously treated chronic lymphocytic leukaemia. Br J Haematol 147: 507-514, 2009.

18. Byrd JC, Marcucci G, Parthun MR, Xiao JJ, Klisovic RB, Moran M, Lin TS, Liu S, Sklenar AR, Davis ME, et al: A phase 1 and pharmacodynamic study of depsipeptide (FK228) in chronic lymphocytic leukemia and acute myeloid leukemia. Blood 105: 959-967, 2005.

19. Cheson BD, Bennett JM, Grever M, Kay N, Keating MJ, O'Brien S and Rai KR: National cancer institute-sponsored working group guidelines for chronic lymphocytic leukemia: revised guidelines for diagnosis and treatment. Blood 87: 4990-4997, 1996.

20. Huang P, Sandoval A, Van Den Neste E, Keating MJ and Plunkett W: Inhibition of RNA transcription: A biochemical mechanism of action against chronic lymphocytic leukemia cells by fludarabine. Leukemia 14: 1405-1413, 2000.

21. Iverson SL and Orrenius S: The cardiolipin-cytochrome c interaction and the mitochondrial regulation of apoptosis. Arch Biochem Biophys 423: 37-46, 2004.

22. Zenkov NK, Menshchikova EB and Tkachev VO: Keap1/Nrf2/ARE redox-sensitive signaling system as a pharmacological target. Biochemistry (Mosc) 78: 19-36, 2013.

23. Trachootham D, Zhang H, Zhang W, Feng L, Du M, Zhou Y, Chen Z, Pelicano H, Plunkett W, Wierda WG, et al: Effective elimination of fludarabine-resistant CLL cells by PEITC through a redox-mediated mechanism. Blood 112: 1912-1922, 2008.

24. Pelicano H, Xu RH, Du M, Feng L, Sasaki R, Carew JS, Hu Y, Ramdas L, Hu L, Keating MJ, et al: Mitochondrial respiration defects in cancer cells cause activation of Akt survival pathway through a redox-mediated mechanism. J Cell Biol 175: 913-923, 2006.

25. Ungerstedt JS, Sowa Y, Xu WS, Shao Y, Dokmanovic M, Perez G, Ngo L, Holmgren A, Jiang X and Marks PA: Role of thioredoxin in the response of normal and transformed cells to histone deacetylase inhibitors. Proc Natl Acad Sci USA 102: 673-678, 2005.

26. Itoh K, Wakabayashi N, Katoh Y, Ishii T, Igarashi K, Engel JD and Yamamoto M: Keap1 represses nuclear activation of antioxidant responsive elements by Nrf2 through binding to the amino-terminal Neh2 domain. Genes Dev 13: 76-86, 1999.

27. Dinkova-Kostova AT, Holtzclaw WD, Cole RN, Itoh $\mathrm{K}$, Wakabayashi N, Katoh Y, Yamamoto M and Talalay P: Direct evidence that sulfhydryl groups of Keap1 are the sensors regulating induction of phase 2 enzymes that protect against carcinogens and oxidants. Proc Natl Acad Sci USA 99: 11908-11913, 2002.

28. Lu SC: Regulation of glutathione synthesis. Curr Top Cell Regul 36: 95-116, 2000.

29. Craig RW: MCL1 provides a window on the role of the BCL2 family in cell proliferation, differentiation and tumorigenesis. Leukemia 16: 444-454, 2002. 
30. Balakrishnan K, Burger JA, Wierda WG and Gandhi V: AT-101 induces apoptosis in CLL B cells and overcomes stromal cell-mediated Mcl-1 induction and drug resistance. Blood 113 149-153, 2009.

31. Zenz T, Häbe S, Denzel T, Mohr J, Winkler D, Bühler A, Sarno A, Groner S, Mertens D, Busch R, et al: Detailed analysis of p53 pathway defects in fludarabine-refractory chronic lymphocytic leukemia (CLL): Dissecting the contribution of $17 \mathrm{p}$ deletion, TP53 mutation, p53-p21 dysfunction and miR34a in a prospective clinical trial. Blood 114: 2589-2597, 2009.

32. Caligaris-Cappio F: Biology of chronic lymphocytic leukemia. Rev Clin Exp Hematol 4: 5-21, 2000.

33. Shao Y, Gao Z, Marks PA and Jiang X: Apoptotic and autophagic cell death induced by histone deacetylase inhibitors. Proc Nat Acad Sci USA 101: 18030-18035, 2004.

34. Okabe S, Tauchi T, Kimura S, Maekawa T, Kitahara T, Tanaka Y and Ohyashiki K: Combining the ABL1 kinase inhibitor ponatinib and the histone deacetylase inhibitor vorinostat: A potential treatment for BCR-ABL-positive leukemia. PLoS One 9: e89080, 2014.

35. Thurn KT., Thomas S, Moore A and Munster PN: Rational therapeutic combinations with histone deacetylase inhibitors for the treatment of cancer. Future Oncol 7, 263-283, 2011.

36. Nimmanapalli R, Fuino L, Stobaugh C, Richon V and Bhalla K: Cotreatment with the histone deacetylase inhibitor suberoylanilide hydroxamic acid (SAHA) enhances imatinib-induced apoptosis of Bcr-Abl-positive human acute leukemia cells Blood 101: 3236-3239, 2003

37. He LZ, Tolentino T, Grayson P, Zhong S, Warrell RP Jr, Rifkind RA, Marks PA, Richon VM and Pandolfi PP: Histone deacetylase inhibitors induce remission in transgenic models of therapy-resistant acute promyelocytic leukemia. J Clin Invest 108: 1321-1330, 2001.
38. VanderMolen KM, McCulloch W, Pearce CJ and Oberlies NH: Romidepsin (Istodax, NSC 630176, FR901228, FK228, depsipeptide): A natural product recently approved for cutaneous T-cell lymphoma. J Antibiot (Tokyo) 64: 525-531, 2011

39. Garcia-Manero G, Yang H, Bueso-Ramos C, Ferrajoli A, Cortes J, Wierda WG, Faderl S, Koller C, Morris G, Rosner G, et al: Phase 1 study of the histone deacetylase inhibitor vorinostat (suberoylanilide hydroxamic acid [SAHA]) in patients with advanced leukemias and myelodysplastic syndromes. Blood 111: 1060-1066, 2008.

40. Kansanen E, Kuosmanen SM, Leinonen H and Levonen AL: The Keap1-Nrf2 pathway: Mechanisms of activation and dysregulation in cancer. Redox Biol 1, 45-49, 2013.

41. Bannai S: Transport of cystine and cysteine in mammalian cells. Biochim Biophys Acta 779: 289-306, 1984.

42. Kitada S, Andersen J, Akar S, Zapata JM, Takayama S, Krajewski S, Wang HG, Zhang X, Bullrich F, Croce CM, et al: Expression of apoptosis-regulating proteins in chronic lymphocytic leukemia: Correlations with in vitro and in vivo chemoresponses. Blood 91: 3379-3389, 1998.

43. Nijhawan D, Fang M, Traer E, Zhong Q, Gao W, Du F and Wang X: Elimination of Mcl-1 is required for the initiation of apoptosis following ultraviolet irradiation. Genes Dev 17: 1475-1486, 2003

44. Adams KW and Cooper GM: Rapid turnover of mcl-1 couples translation to cell survival and apoptosis. J Biol Chem 282: 6192-6200, 2007.

45. Inoue S, Walewska R, Dyer MJ and Cohen GM: Downregulation of Mcl-1 potentiates HDACi-mediated apoptosis in leukemic cells. Leukemia 22: 819-825, 2008.

46. Ghezzi P: Regulation of protein function by glutathionylation. Free Radic Res 39: 573-580, 2005.

47. An X, Schulz VP, Li J, Wu K, Liu J, Xue F, Hu J, Mohandas N and Gallagher PG: Global transcriptome analyses of human and murine terminal erythroid differentiation. Blood 123: 3466-3477, 2014. 